\title{
How can we understand the global distribution of the solar cycle signal on the Earth's surface?
}

\author{
Kunihiko Kodera $^{1}$, Rémi Thiéblemont ${ }^{2}$, Seiji Yukimoto ${ }^{3}$, and Katja Matthes ${ }^{4,5}$ \\ ${ }^{1}$ Institute for Space-Earth Environmental Research, Nagoya University, Nagoya, 464-8601, Japan \\ ${ }^{2}$ Laboratoire Atmosphères Milieux Observations Spatiales, 78280 Guyancourt, France \\ ${ }^{3}$ Meteorological Research Institute, Tsukuba, 305-0052, Japan \\ ${ }^{4}$ Research Division Ocean Circulation and Climate, GEOMAR Helmholtz Centre for Ocean Research, 24105 Kiel, Germany \\ ${ }^{5}$ Christian-Albrechts Universität zu Kiel, 24105 Kiel, Germany \\ Correspondence to: Kunihiko Kodera (kodera@isee.nagoya-u.ac.jp)
}

Received: 13 February 2016 - Published in Atmos. Chem. Phys. Discuss.: 25 February 2016

Revised: 12 September 2016 - Accepted: 28 September 2016 - Published: 19 October 2016

\begin{abstract}
To understand solar cycle signals on the Earth's surface and identify the physical mechanisms responsible, surface temperature variations from observations as well as climate model data are analysed to characterize their spatial structure. The solar signal in the annual mean surface temperature is characterized by (i) mid-latitude warming and (ii) no overall tropical warming. The mid-latitude warming during solar maxima in both hemispheres is associated with a downward penetration of zonal mean zonal wind anomalies from the upper stratosphere during late winter. During the Northern Hemisphere winter this is manifested by a modulation of the polar-night jet, whereas in the Southern Hemisphere, the upper stratospheric subtropical jet plays the major role. Warming signals are particularly apparent over the Eurasian continent and ocean frontal zones, including a previously reported lagged response over the North Atlantic. In the tropics, local warming occurs over the Indian and central Pacific oceans during high solar activity. However, this warming is counterbalanced by cooling over the cold tongue sectors in the southeastern Pacific and the South Atlantic, and results in a very weak zonally averaged tropical mean signal. The cooling in the ocean basins is associated with stronger cross-equatorial winds resulting from a northward shift of the ascending branch of the Hadley circulation during solar maxima. To understand the complex processes involved in the solar signal transfer, results of an idealized middle atmosphere-ocean coupled model experiment on the impact of stratospheric zonal wind changes are compared with solar signals in observations. Model integration of 100 years of
\end{abstract}

strong or weak stratospheric westerly jet condition in winter may exaggerate long-term ocean feedback. However, the role of ocean in the solar influence on the Earth's surface can be better seen. Although the momentum forcing differs from that of solar radiative forcing, the model results suggest that stratospheric changes can influence the troposphere, not only in the extratropics but also in the tropics through (i) a downward migration of wave-zonal mean flow interactions and (ii) changes in the stratospheric mean meridional circulation. These experiments support earlier evidence of an indirect solar influence from the stratosphere.

\section{Introduction}

The influence of solar activity on the Earth's surface, especially that of the 11-year solar cycle, has been debated for a long time (e.g. Pittock, 1978; Legras, 2010). The climate impact of solar influence is generally assessed in terms of the radiative forcing (e.g. IPCC, 2013). Recent direct measurements from space reveal that changes in the total solar irradiance (TSI) associated with the 11-year solar cycle are about $0.1 \%\left(1.3 \mathrm{~W} \mathrm{~m}^{-2}\right)$ (Kopp and Lean, 2011). Such small variations are not expected to have a significant impact on surface climate, and so several mechanisms have been proposed that act to amplify the initially small solar effects. One amplification mechanism is the enhancement of the direct TSI effect at the ocean surface due to a feedback of water vapour transport in the tropical Pacific (Meehl et al., 2008, 2009). Another 
possible amplification mechanism works through a change in the solar spectrum, in particular in the ultraviolet (UV) range, directly affecting the stratopause region and enhancing temperatures and ozone concentrations during the solar cycle. The amplification and the downward penetration of the small initial solar signal occur through stratospheric dynamical processes (e.g. Kodera and Kuroda, 2002). The impact of cosmic rays on surface temperature through changes in cloud cover has also been proposed (Svensmark and FriisChristensen, 1997).

Besides an apparently small direct solar effect, another problem of explaining solar influence on climate is the rather unstable relationship between the 11-year solar cycle and the Earth's global mean surface temperature, as a breakdown or even the reversal of the relationship occurs during different time periods (e.g. Nitta and Yoshimura, 1993; Georgieva et al., 2007; Souza-Echer, 2012). However, Zhou and Tung (2010) extracted a global spatial pattern of sea surface temperature (SST) variations associated with the solar cycle by applying a composite mean difference (CMD) projection method, particularly relevant to estimate the robustness of a global spatial signal. This method segregates data into groups of high and low solar activity during the 11-year cycle. A global spatial pattern is then obtained from the composite mean difference between the high and low solar group. Finally, the original data are projected onto this CMD spatial pattern, resulting in a time series. The method is successful when the correlation between the resulting time series and the solar forcing is high. They demonstrated that the coefficients of this CMD pattern projected onto the global SST field show a steady and highly robust relationship with the solar activity over more than 10 solar cycles (represented by the TSI for the past 153 years reconstructed by Y.-M. Wang et al., 2005). This indicates that a global spatial pattern, rather than a globally averaged temperature, is crucial to understanding solar influences at the surface.

Various studies of the solar influence on weather and climate were reviewed by Gray et al. (2010). Here, we do not attempt to extensively review previous works, but rather look for consistent aspects of the solar signals reported in many independent studies. The surface response to solar forcing is regionally distributed; that means that the solar signal is influenced by the internal dynamics of the climate system. Our paper aims to suggest supplementary physical processes that may help to better understand the global distribution of the solar signal. In the following, we will particularly show that the atmosphere-ocean interactions may play an important role in determining surface solar signal over baroclinic zones and tropical cold tongue regions.

Surface temperature and pressure have been measured for more than 100 years. Thus, the relationship between surface temperature variations and solar activity can be investigated using a global historical dataset. Because sea surface temperature (SST) is more persistent than the sea-level pressure, long-term variations can be more easily detected in the tem- perature field. Therefore, we investigate mainly surface temperature variation from the historical data, complemented by pressure or geopotential height fields with a modern dataset. Direct measurement of the solar UV is only recent, but a record of the sunspot number, which is a proxy of the solar extreme ultraviolet (EUV), is available from the 18th century. The solar EUV produces the ionization in the Earth's upper atmosphere. Therefore, change in the solar EUV radiation is felt on the Earth's surface as change in geomagnetic field induced by the electric current in the ionosphere. It is, thus, possible to associate the variation of sunspot number with the solar EUV activity. Comparison of the variation calculated from Earth's magnetic field demonstrates excellent agreement between the $10.7 \mathrm{~cm}$ solar radio flux (F10.7) and the sunspot number (Svalgaard, 2007). Therefore, both can be used as a proxy of the solar irradiance variation.

Annual mean surface temperature anomalies related to the solar cycle have been studied using various methods and different historical global datasets covering between 120 and 150 years. Lohmann et al. (2004) calculated the correlation coefficient between the proxy solar irradiance from Lean et al. (1995) and band-pass (between 9- and 5-year period) filtered SSTs reconstructed by Kaplan et al. (1998) from 1856 to 2000. Lean and Rind (2008) extracted solar signals by applying a multiple linear regression analysis to surface temperatures reconstructed by the University of East Anglia Climatic Research Unit F (Brohan et al., 2006) for the period 1889-2006. A similar multiple linear regression analysis was conducted by Tung and Zhou (2010), who compared the regression analysis of two different historical datasets, namely NOAA's Extended Reconstructed Sea Surface Temperatures (ERSST) and the Hadley Centre Sea Ice and Sea Surface Temperature (HadISST) dataset (Rayner et al., 2003), to confirm consistent features of the solar signal. Gray et al. (2013) performed a lagged multiple linear regression analysis to investigate delayed components in the solar signal using the HadISST dataset. Despite different reconstructions and analysis methods, common features are seen during high solar activity in the surface temperatures: a midlatitude warming, and a tropical cooling in the southeastern Pacific and the South Atlantic. Note that this cooling is different from the La Niña-like pattern previously reported (van Loon et al., 2007; Meehl et al., 2008, 2009) and will be discussed in more detail below.

We first compare the analysis results of a historical surface temperature dataset with those of a modern dataset to identify the fundamental global features of surface temperature variations related to the solar cycle, i.e. the observed surface solar signals. Next, we study the vertical structure of the solar signal with recent data to identify possible physical mechanisms producing the surface solar signals. Identification of the causes and characteristics of solar signals is particularly difficult for decadal-scale periodic variations because strong feedbacks exist on these timescales in the climate system. To better understand the mechanisms produc- 
ing the surface solar signal, we revisit results from an idealized middle atmosphere-ocean coupled general circulation experiment where a momentum forcing has been applied in the stratosphere (Yukimoto and Kodera, 2007).

The remainder of this paper is organized as follows. After describing the data and method of analysis in Sect. 2, characteristics of the solar signal in atmospheric as well as oceanic variables are described in Sect. 3. To understand the complex processes for the solar signal transfer involving stratospheretroposphere-ocean coupling, results of an idealized numerical experiment are compared with observed solar signals in Sect. 4. To get insight into a centennial solar variation such as the Maunder Minimum, the effect of centennial-scale stratospheric circulation changes on the troposphere is briefly studied in Sect. 5. Finally, discussions and a summary about the possible mechanisms producing the solar influence on the Earth's surface are given in Sect. 5.

\section{Data and analysis}

\subsection{Data}

This study combines the analysis of a historical SST dataset to characterize the surface response to the 11-year solar cycle, with a modern reanalysis dataset to investigate the underlying dynamical processes. For the historical dataset, we use the NOAA Extended Reconstructed SST v3b (ERSST), described by Smith et al. (2008) and available at http://www.esrl.noaa.gov/psd/data/gridded/data.noaa. ersst.html. The ERSST dataset spans more than 160 years from 1854 to the present, with monthly resolution, and a spatial resolution of $2^{\circ}$ longitude $\times 2^{\circ}$ latitude from $88^{\circ} \mathrm{N}$ to $88^{\circ} \mathrm{S}$ and 0 to $358^{\circ} \mathrm{E}$. Given the sparsity of observations before 1880 (Smith and Reynolds, 2003), we limited the present study to the period 1880-2010. To examine the tropospheric and stratospheric dynamical response to the solar cycle, we use the ERA-Interim atmospheric reanalysis produced by the European Centre for Medium-Range Weather Forecasts (ECMWF) (Dee et al., 2011). We used the ERAInterim (ERA-I) dataset from 1 January 1979 to 2010. In this study, we used monthly mean data, provided on 23 pressure levels from 1000 to $1 \mathrm{hPa}$ with a spatial resolution of $2.5^{\circ}$ longitude $\times 2.5^{\circ}$ latitude.

\subsection{Multiple linear regression model}

Following numerous earlier studies (e.g. Lean and Rind, 2008; Frame and Gray, 2010; Chiodo et al., 2014; Mitchell et al., 2015a, b), the ocean and atmosphere responses to solar variations are examined using a multiple linear regression (MLR) model. This technique can isolate the effects of different forcings, represented by explanatory variables (or regressors), on the variance of a time-dependent variable (or predictand). Annual signals are extracted by applying the MLR to continuous monthly resolved time series. Monthly or sea- sonal signals ( 2 to 3 consecutive months) are diagnosed by applying the MLR to time series of the individual month or season (i.e., the seasonal average is performed prior to the MLR), respectively. All data time series have the seasonal cycle removed before the MLR, as well as before any seasonalaverage calculations.

The MLR model is applied at each location and is given by

$$
\begin{aligned}
& X(t)=A \cdot \mathrm{CO}_{2}(t)+B \cdot \mathrm{N} 3.4(t)+C \cdot \mathrm{F} 10.7(t-\Delta t) \\
& +D \cdot \mathrm{AOD}(t)+E \cdot \mathrm{QBOa}(t)+F \cdot \mathrm{QBOb}(t)+\epsilon(t),
\end{aligned}
$$

where $X(t)$ is the time-dependent variable, the first six terms on the right-hand side of the equation correspond to the product of one time-dependent explanatory variable (e.g. $\left.\mathrm{CO}_{2}(t)\right)$ and its regression coefficient (e.g. $A$ ) and the last term $\varepsilon(t)$ is the residual error.

The explanatory variables considered for the MLR describe variability sources that are demonstrated to have a significant impact on the surface, troposphere and middle atmosphere dynamics, and have been broadly used in solarclimate studies based on model and reanalysis (e.g. Chiodo et al., 2014; Mitchell et al., 2015a, b). The explanatory variables are defined as follows: the $\mathrm{CO}_{2}$ concentration (Meinshausen et al., 2011) (available at http://climate.uvic.ca/EMICAR5/ forcing_data/RCP85_MIDYR_CONC.DAT) to account for the increase in anthropogenic forcing; the Niño 3.4 index derived from the ERSST v3b dataset; the $F 10.7 \mathrm{~cm}$ solar radio flux index (available at http://lasp.colorado.edu/lisird/tss/ noaa_radio_flux.html); and the global aerosol optical depth (AOD) at $550 \mathrm{~nm}$ updated from Sato et al. (1993) to represent volcanic effects and two stratospheric quasi-biennial oscillation (QBO) orthogonal indices (QBOa and QBOb), defined as the first two principal components of the ERA-I zonal mean zonal wind in the latitude interval $\left(10^{\circ} \mathrm{S}, 10^{\circ} \mathrm{N}\right)$ and pressure-height interval (70-5) $\mathrm{hPa}$, respectively.

QBO regressors and F10.7 index are only available from the mid-20th century, so that QBO regressors are not included in the MLR and the F10.7 index is replaced by the sunspot numbers when the long-term historical SST dataset is analysed. Sensitivity tests of the MLR model revealed that including or removing the stratospheric QBO regressors for the period 1979-2010 negligibly affects the solar regression coefficients and their statistical significance, in particular in the troposphere. Although the F10.7 cm index more directly represents the irradiance variability in the UV band than the sunspot number (Tapping, 2013), both indices concur at annual timescales: a correlation coefficient of 0.997 between the annually averaged F10.7 and sunspot number time series is found for the period 1965-2012. The solar regression coefficient used in our study assumes that a difference of 130 solar flux units $\left(1 \mathrm{sfu}=10^{-22} \mathrm{~W} \mathrm{~m}^{-2} \mathrm{~Hz}^{-1}\right)$ or 100 sunspots represents the difference between the 11-year solar cycle maximum and minimum. 
To investigate the effect of the ocean memory on the surface response to solar variability (e.g. Gray et al., 2013; Thiéblemont et al., 2015), we calculated the MLR at different time lags ( $\Delta t$ in months or years) with respect to the solar regressor. The Arctic Oscillation (AO) or the North Atlantic Oscillation (NAO) is a climate mode of variability, which is partly driven by solar variability as will be shown later. Hence, it is not appropriate to include its index in an MLR model, which aims to examine the solar cycle effect on surface climate.

When applying regression techniques, it is essential to carefully consider possible autocorrelation in the residual to assess statistical significance of the regression coefficients. Autocorrelation in the residual leads to an underestimation of the regression coefficient uncertainties, and thus a narrowing of the confidence intervals. A common method employed to circumvent the residual autocorrelation problem is to treat the residual term as an autoregressive process (Tiao et al., 1990). The first step of the procedure, also called prewhitening, consists of correcting both the predictors and the predictand $(X)$ with the autocorrelation coefficient of the residual term estimated from a first application of the regression model. The prewhitening procedure is then repeated on the modified predictors and predictand until the residual is no longer significantly autocorrelated. The statistical significance of the autocorrelation is assessed with a DurbinWatson test. The application of the Tiao et al. method can be found in several papers examining the solar signal (e.g. Austin et al., 2008; Mitchell et al., 2015b). We generally found that a single application of the prewhitening procedure was sufficient to remove the residual autocorrelation almost completely (more than $95 \%$ of the grid points). Once the prewhitening step has been performed, the statistical significance of the regression coefficients is calculated using a two-tailed Student's $t$ test.

The use of the MLR approach to separate the contribution of different factors to climate variability has inherent limitations that should be kept in mind when analysing the results. The MLR particularly relies on several assumptions that may not be valid in all cases. However, composite analysis of the monthly mean data based on high and low levels of solar activity (e.g. Kuroda and Kodera, 2002; Lu et al., 2011) also produces similar solar signals as those obtained from the MLR method (Figs. 6, 7). Therefore, in spite of the limitations, the MLR method may be useful to get approximate solar signals (Kuchar et al., 2015). We note that highly non-linear responses can be produced through the interaction between different forcings: for example, between El NiñoSouthern Oscillation (ENSO) and solar signals (Marsh and Garcia, 2007), solar and QBO signals (Matthes et al., 2013), as well as volcanic and solar signals (Chiodo et al., 2014). Usually this kind of interaction occurs at a specific location and time, which needs to be investigated in separate studies. Sophisticated attribution methods that can account for nonlinearity have been used, such as machine learning methods
(Blume et al., 2012) or optimal detection (Stott et al., 2003; Mitchell, 2016). Although these methods use advanced statistical techniques, it is difficult to relate the conclusions to specific physical mechanisms.

\section{Solar signal}

\subsection{Surface temperature signal}

As mentioned in the Introduction, Zhou and Tung (2010; hereafter ZT2010) calculated CMDs between high- and lowactivity periods of the 11-year solar cycle using the ERSST dataset. In their analysis, data near the World War II period (1942-1950) were excluded. We performed the same CMD analysis using the same dataset as ZT2010, but starting in 1880 instead of 1854 . We confirm the results of ZT2010 in Fig. 1a. The correlation coefficient between the expansion coefficients of the extracted pattern and the solar index shows a similar high correlation (0.69).

To assess the stability of the relationship between SSTs and the solar cycle, the use of a long dataset is crucial. However, historical datasets have problems with spatial coverage and inhomogeneity of the observing systems. This drawback may be compensated by a comparison with a recent global dataset assimilating satellite observations. Figure $1 \mathrm{~b}$ shows the surface solar signal extracted by MLR using the ERA-I and $F 10.7 \mathrm{~cm}$ radio flux time series (solar index) as one of the explanatory variables for the period from 1979 to 2010. Despite the short time period of only three solar cycles, the results show a similar pattern in surface temperature to those obtained from longer historical datasets. Common features in the spatial structure of the solar signal in surface temperatures include (i) (subpolar regions): warming around $45-60^{\circ} \mathrm{N}$ over the Eurasian continent and cooling over the west of Greenland; (ii) (mid-latitudes): warming over the ocean basins around $30-45^{\circ}$ latitudes in the Northern Hemisphere (NH) as well as in the Southern Hemisphere (SH); (iii) (tropics): warming over the Indian Ocean and the central Pacific, and cooling in the eastern Pacific and the Atlantic, particularly in the SH. These characteristics are also found in a number of other studies, cited in the Introduction, that use different analysis techniques. In spite of overall similarities, large differences can be found in some regions, such as over the subtropical eastern Pacific, east of Hawaii. It shows large warming in the historical data (Fig. 1a), but cooling in the modern era data (Fig. 1b). It is, however, difficult to identify whether the difference in short-term data is merely due to statistical fluctuations, or related to a change in basic climatological states caused by other factors, such as global warming or ocean circulation change. Here, we concentrate on the stable solar response to first understand how it is produced at the Earth's surface. To investigate the solar signals over the ocean basins specifically, equatorward gradients of climatological SSTs are shown in Fig. 1c. The regions where warming during solar maxima occurs roughly correspond to 
(a)

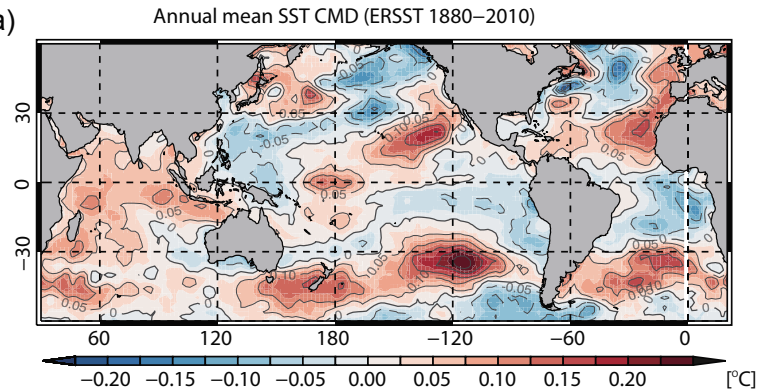

(b)

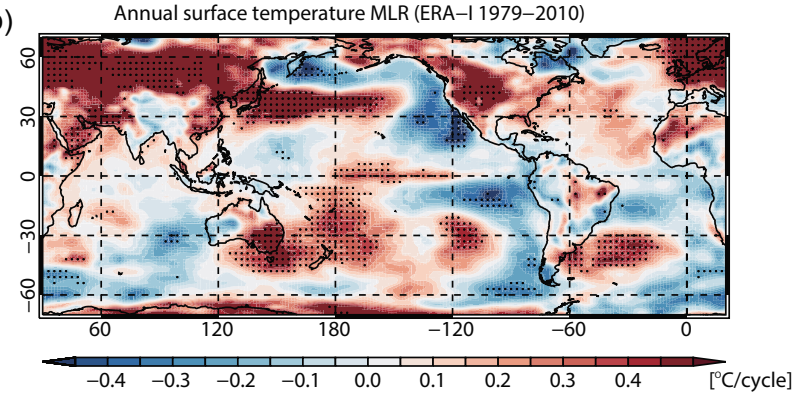

(c)

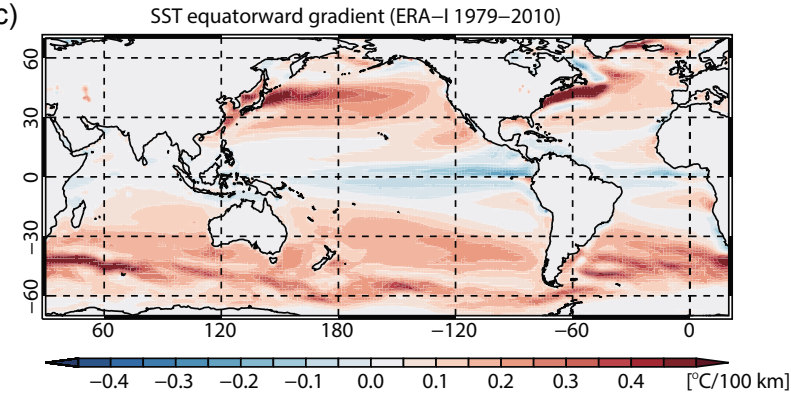

Figure 1. $T$ (a) Annual mean SST anomaly extracted by the same CMD analysis as in Zhou and Tung (2010) for the period 18802010. (b) Annual solar index regression coefficient of the surface temperature derived by applying the MLR model to ERA-I data for the period 1979-2010. Stippled areas indicate statistical significance at the $95 \%$ level. (c) Equatorward gradient of annual mean climatological SST.

regions of strong meridional SST temperature gradients. The case of solar signals over the North Atlantic frontal zone is more complicated (see Fig. 1a), and in fact solar signals over the North Atlantic are delayed by about 3 years (Gray et al., 2013; Scaife et al., 2013; Andrews et al., 2015; Thiéblemont et al., 2015), and will be discussed later. Note also that regions with cool solar signals in the tropics coincide with sectors of the cold tongue over the equatorial eastern Pacific and the Atlantic. This kind of temperature pattern is quite different from the expected impact of TSI variations from an energy balance model. Stevens and North (1996) estimated a warming in the tropics from such a model, in particular over the continents.

To identify the physical mechanisms responsible for the surface solar signals, a comparison of the surface temper- ature pattern associated with other forcings has been performed similarly to Lean and Rind (2008). The zonal mean surface temperature pattern extracted by an MLR is shown in Fig. 2. In the MLR model of Lean and Rind (2008), who used historical data, anthropogenic forcing combines anthropogenic aerosol and greenhouse gases effects. Although their anthropogenic signal shows a rather uniform warming latitudinally that differs from that of the present study, the other signals (i.e. ENSO, volcanic and solar) are similar. ENSOrelated temperature variations (Fig. 2a) are confined to the tropics. The response to volcanic aerosol (Fig. 2b) is a global cooling, whereas the response to anthropogenic greenhouse gas forcing (Fig. 2c) is characterized by a large warming in the polar region of the $\mathrm{NH}$. A cooling trend is also found in the Southern Ocean around $60^{\circ} \mathrm{S}$. However, it could also result from ozone depletion (Thompson et al., 2011) because trends in $\mathrm{CO}_{2}$ and ozone concentration cannot be well separated due to the short analysis period. The solar signal is large in mid-latitudes in both hemispheres (Fig. 2d) as already reported in Lean and Rind (2008). The reason for such a latitudinal distribution has not been addressed, however. If the surface solar signal originates from the absorption of the solar energy at the Earth's surface, we should expect a higher solar signal in the tropics similar to the climatological SST distribution (Fig. 2e). However, a large solar signal is observed in the frontal zones where the meridional gradient of surface temperature is the largest (Fig. 2f) and where the interaction between the atmosphere and the ocean is particularly strong (Nakamura et al., 2008). This suggests, thus, a possible role of atmosphere-ocean interaction in the baroclinic zone in the modulation and amplification of the solar signal.

To explain solar signals at the surface in high latitudes, the role of the annular mode (AM) (Thompson and Wallace, 2000 ) in the NH (NAM) in mediating tropospheric solar signals has been suggested (e.g. Baldwin and Dunkerton, 2005). The AM in the SH is called the SAM. However, in the SH, Lu et al. (2011) found little relationship between the solar cycle and the SAM on the surface. The surface signal of NAM and SAM are also called Arctic Oscillation (AO) and Antarctic Oscillation (AAO), respectively. The question we address here is the role of AM in a global perspective: how does the solar signal comparatively manifest in the $\mathrm{SH}$ and in the $\mathrm{NH}$ ? Figure 3 compares solar signals with annular modes in the two hemispheres. In NH winter (DJF), solar signals exhibit a similar pattern to the NAM: a warming over the Eurasian continent and the ocean basins along $30-45^{\circ} \mathrm{N}$ latitudes, and a cooling west of Greenland. Stronger westerly winds associated with the NAM and surface solar signals occur at lower latitudes over the American continent than over the Eurasian continent. This means that the NAM is not strictly annular, but also contains a stationary planetary wave structure. It should be noted that the spatial pattern of the solar signal is similar to that of the NAM. In SH spring (SON), solar signals are characterized by a warming in mid-latitudes associated with anomalous westerlies around $40-50^{\circ} \mathrm{S}$. However, the 
Zonal mean surface temperature (1979-2010)
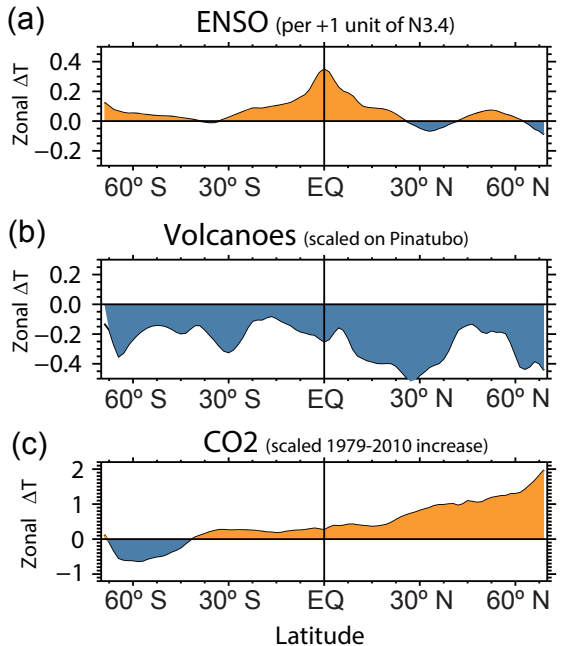
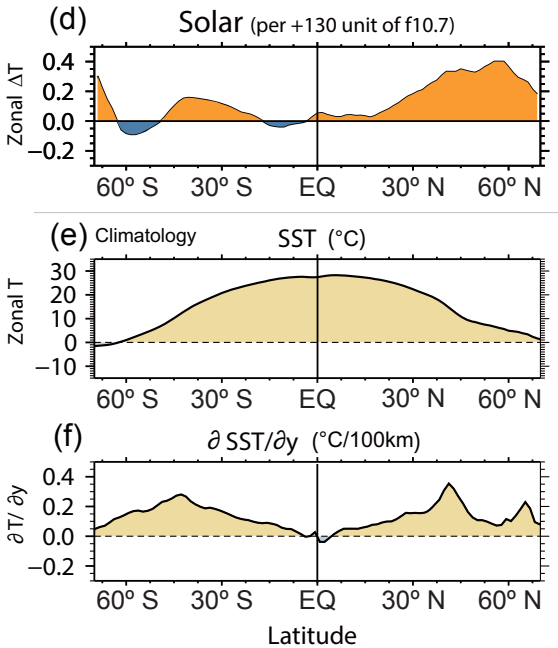

Figure 2. MLR analysis of the annual zonal mean surface temperature from ERA-I, calculated for the period 1979-2010, for (a) ENSO, (b) volcanic activity and (c) $\mathrm{CO}_{2}$ concentration, and (d) solar activity. Climatological zonal mean SSTs and their equatorward meridional gradient are also shown in (e) and (f), respectively.

(a) Solar U500

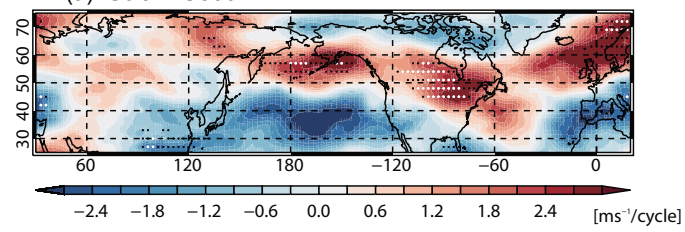

(b) Solar T1000

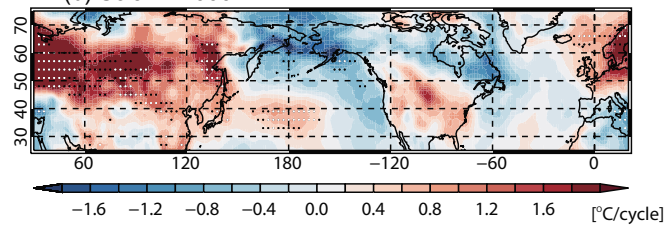

1979-2010 $\mathrm{NH}$ (DJF)

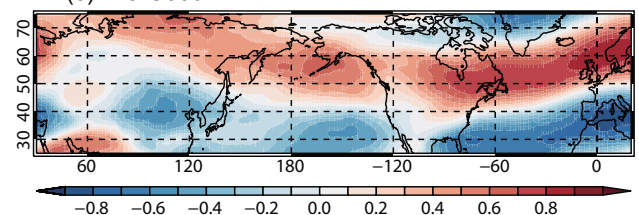

(f) AO T1000

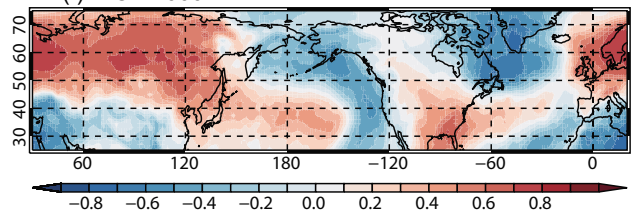

(c) Solar U500

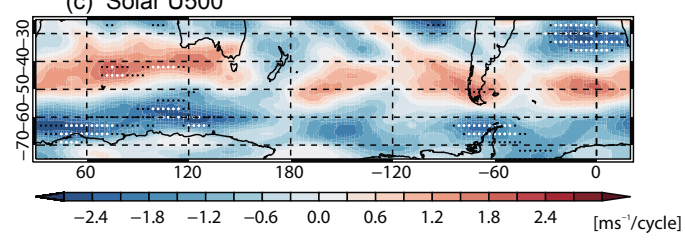

(d) Solar T1000

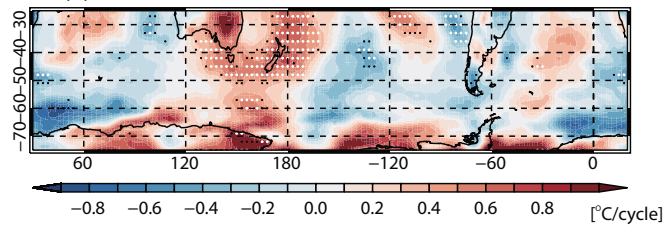

$\mathrm{SH}$ (SON)

(g) AAO U500

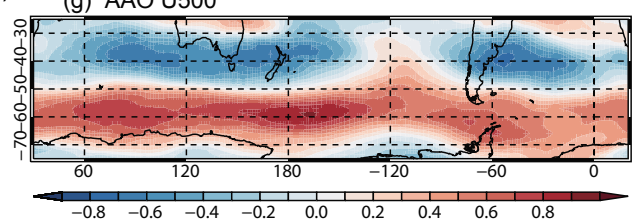

(h) AAO T1000

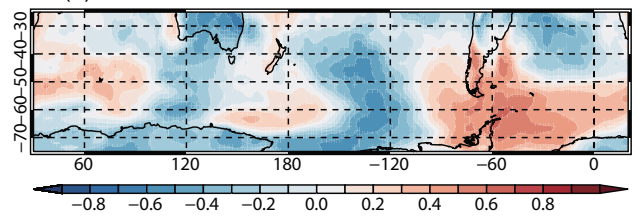

Figure 3. Solar regression coefficient extracted by the MLR technique for the DJF mean NH (a) $500 \mathrm{hPa}$ zonal mean wind, and (b) surface temperature. Panels (c and d): same as (a and b), but for the SON mean in the SH. Panels (e and f): same as (a and b), except for the correlation with surface NAM index. Panels ( $\mathbf{g}$ and $\mathbf{h})$ : same as (c and $\mathbf{d})$, except for the surface SAM index. The period of analysis is 1979-2010. Stippled regions with black and white dots indicate statistical significance at the 90 and $95 \%$ level, respectively. 
(a) June

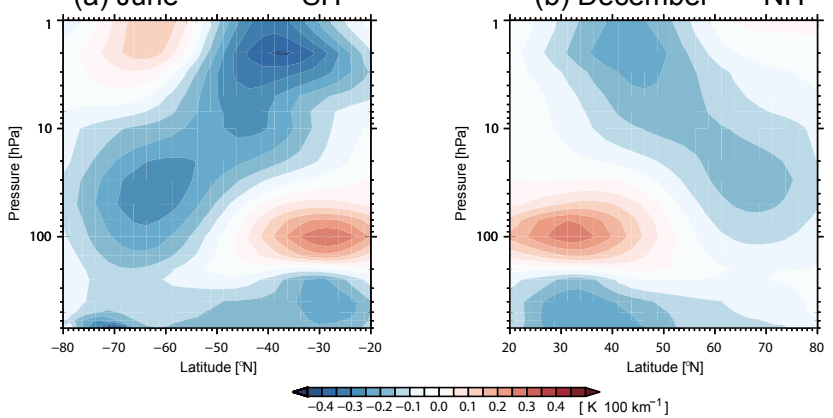

Figure 4. Meridional sections of the climatological poleward temperature gradient around the winter solstice: (a) SH June, (b) $\mathrm{NH}$ December.

SAM pattern typically involves a strong warming around the Antarctic Peninsula and the southern tip of the South American continent (Thompson and Wallace, 2000; Gillett et al., 2006) in association with anomalous westerlies near the polar region around $55-65^{\circ} \mathrm{S}$. This is the reason why solar signals are not projected to the $\mathrm{SAM}$ in the $\mathrm{SH}$, unlike to the $\mathrm{NH}$.

\subsection{Zonal mean vertical structure}

Since the surface solar signals during the recent (1979-2010) period is very similar to that of the longer historical period (1880-2010) (Fig. 1), we may gain further insight into the processes responsible for the solar signal transfer from the stratosphere to the troposphere and the ocean by analysing the modern dataset in more detail. First of all, it should be noted that there are two kinds of westerly jets in the middle atmosphere. Climatological poleward temperature gradient during winter solstice (June in the SH, and December in the $\mathrm{NH}$ ) is displayed in Fig. 4. The meridional temperature gradient is large in the subtropics of the upper stratosphere due to solar UV heating, while in the lower stratosphere, the gradient is strong around the polar-night region due to longwave cooling. They are respectively connected to the subtropical and polar-night jet. From this, we can expect that the variation in the solar UV heating first manifests in the subtropics of the stratopause region.

Figure 5 shows solar signals in the annual mean (a) zonal mean zonal wind, (b) zonal mean air temperature and (c) pressure coordinate vertical velocity in the tropical troposphere using the same MLR analysis as in Fig. 1b. The results of similar MLR analyses using meteorological reanalysis data have also been published (e.g. Frame and Gray, 2010; Chiodo et al., 2014; Mitchell et al., 2015a). During periods of high solar activity, warming signals appear at three levels: the upper stratosphere-stratopause $(5-1 \mathrm{hPa})$, the lower to middle stratosphere $(100-20 \mathrm{hPa})$ and the troposphere $(1000$ $300 \mathrm{hPa}$ ) (Fig. 5a). The warming around the stratopause extends globally from the tropics to the polar regions, while the warming in the lower stratosphere is confined to the trop-
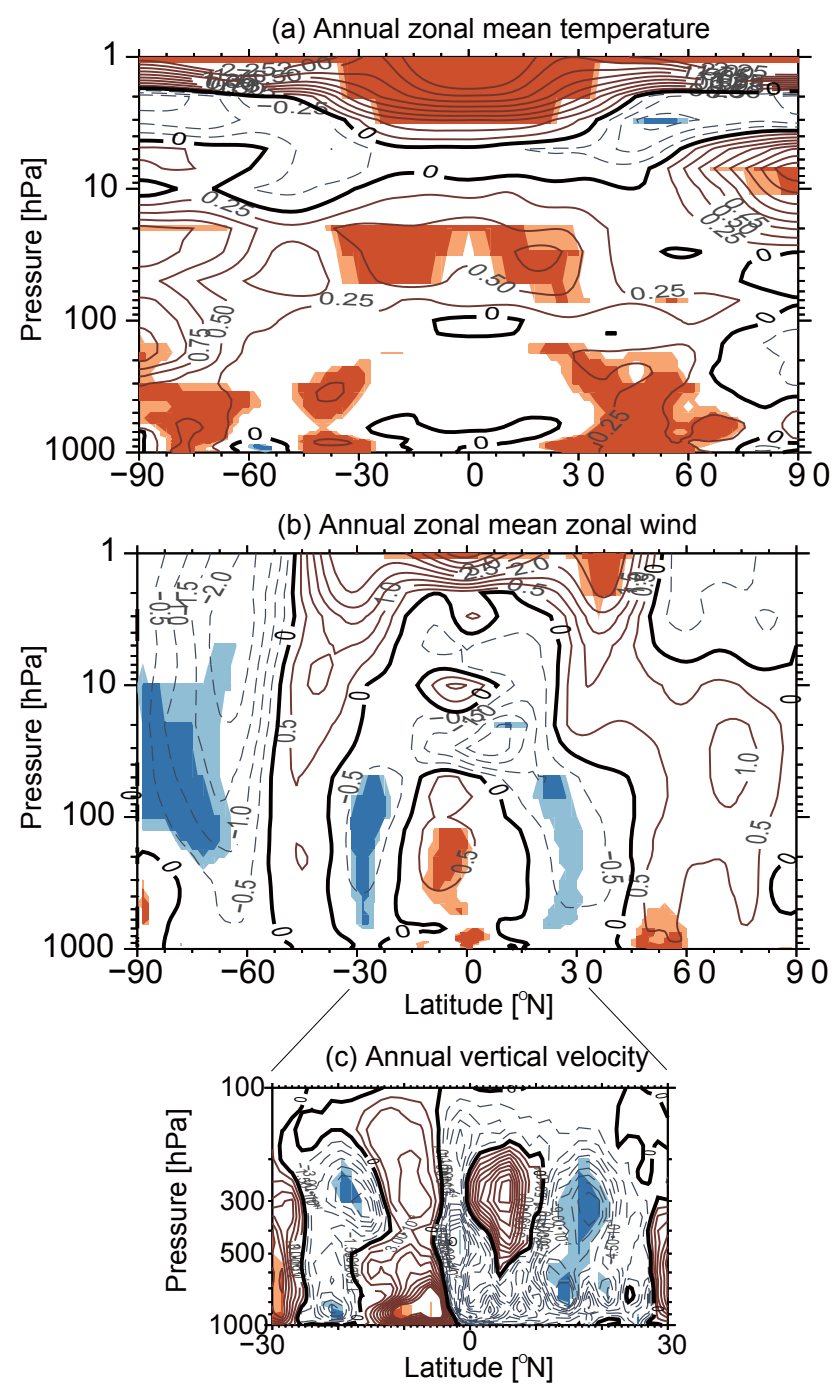

Figure 5. Solar regression coefficients of the annual zonal mean (a) air temperature, (b) zonal wind and (c) vertical velocity in the tropical troposphere. Solid (dashed) contours indicate positive (negative) values and are drawn every (a) $0.25 \mathrm{~K}$, (b) $0.5 \mathrm{~m} \mathrm{~s}^{-1}$ and (c) $5 \mathrm{~m} \mathrm{day}^{-1}$. Areas of 90 and $95 \%$ statistical significance are shown by light and dark shading, respectively, in red (positive) and blue (negative).

ics. The associated stronger meridional temperature gradient in the subtropical upper stratosphere is connected, by the thermal-wind relationship, to enhanced subtropical jets around $30-40^{\circ}$ latitude in both hemispheres in the upper stratosphere (Fig. 5b). Stronger subtropical jets extend farther to lower altitudes in association with a warming in the tropical lower stratosphere. The narrow latitudinal extent of the zonal mean zonal wind anomalies at mid-latitudes of the middle-lower stratosphere in Fig. 5 is difficult to explain only from a radiative heating change. The differences in the latitudinal structure of the warming suggest that the warming in the stratopause-upper stratosphere has a radiative origin, 

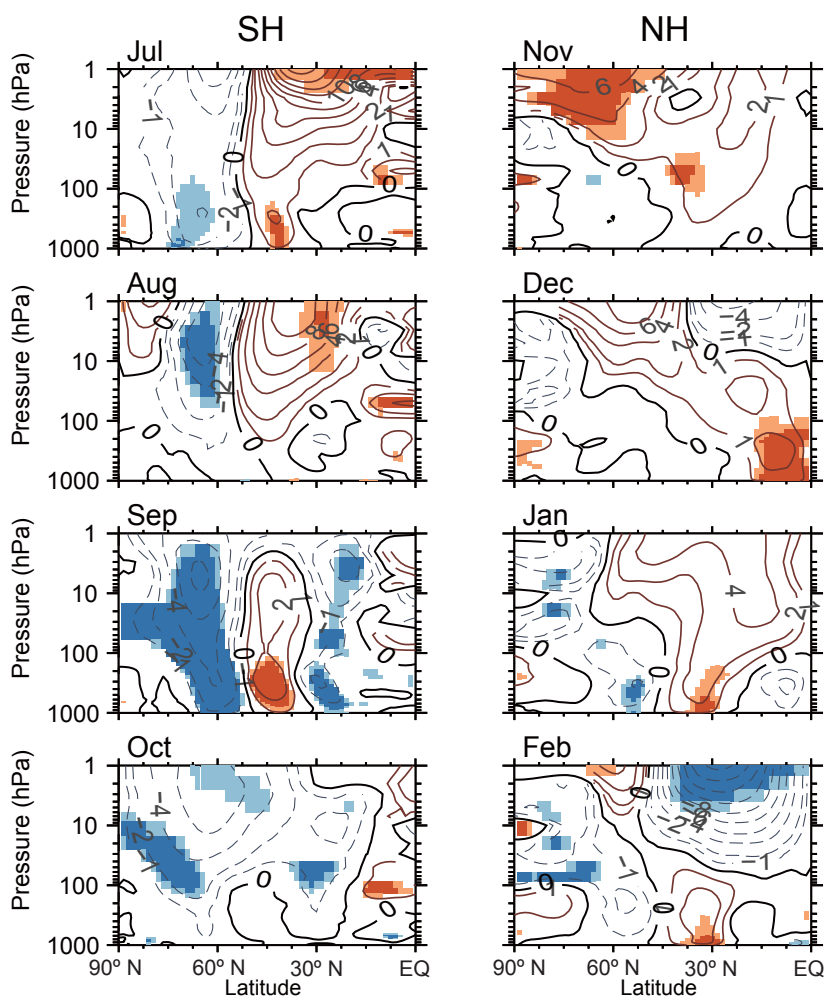

Figure 6. Monthly solar regression coefficient of zonal mean zonal winds in (left) July, August, September and October in the SH, and (right) November, December, January and February in the NH. Solid (dashed) contours indicate positive (negative) values and are drawn every $1 \mathrm{~m} \mathrm{~s}^{-1}$. Areas of 90 and $95 \%$ statistical significance are shown by light and dark shading, respectively, in red (positive) and blue (negative).

while for the second warming in the middle to lower tropical stratosphere, dynamical process plays an important role as suggested in previous studies (e.g. Kodera and Kuroda, 2002; Hood and Soukharev, 2012).

In the troposphere, a statistically significant warming occurs in the extratropics around $40-45^{\circ}$ latitude in both hemispheres (Fig. 5a), similar to that of the surface temperature anomalies in Fig. 1. Warming also occurs over Antarctica in association with a weakening of the high-latitude westerly flow. Note that there is practically no warming in the entire tropical troposphere from the surface to the tropopause. This does not mean that there is no solar influence in this region, but temperature variations in the tropical troposphere are generally small due to feedback with convective activity (Eguchi et al., 2015). Therefore, the response in vertical velocity is crucial in the tropical troposphere, although it is not directly measured. Solar signals in the vertical velocity are generally downward around the equator, but upward in off-equatorial regions around $15-20^{\circ}$ latitude (Fig. 5c). Note also that solar signals in the zonal mean zonal wind are symmetric around the equator in the upper stratosphere (Fig. 5b).
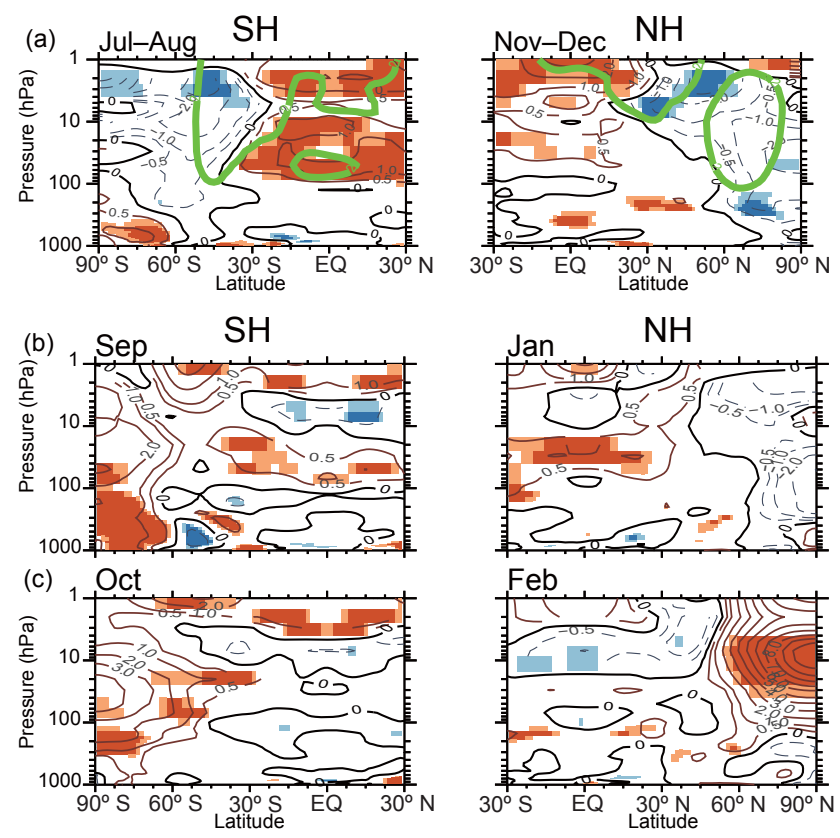

Figure 7. (a) Same as Fig. 6, except for 2-month mean air temperature, July-August in the SH (left), and November-December in the $\mathrm{NH}$ (right). Green lines indicate $2 \mathrm{~m} \mathrm{~s}^{-1}$ contours of the corresponding zonal mean zonal wind. (b) Same as (a), except for monthly mean temperature in September (left) and January (right). (c) Same as (b), except for October (left) and February (right). The contour interval for temperature is $0.5 \mathrm{~K}$.

However, in polar regions, the zonal mean winds in the lower stratosphere differ markedly between the NH and SH. This can be seen more clearly as differences in the seasonal march in Fig. 6 for monthly solar signals in zonal mean winds during $\mathrm{SH}$ and $\mathrm{NH}$ winter. In early winter, the subtropical jet develops in the upper stratosphere in both hemispheres. In the $\mathrm{NH}$, anomalous westerlies shift poleward and downward to the troposphere, and the stratospheric polar-night jet weakens significantly in February. In the SH, however, the poleward shift is small and the strong anomalous westerlies descend in the mid-latitude troposphere, forming a pair of westerly and easterly zonal mean wind anomalies at high latitudes in September.

Solar signals in zonal mean temperature and extracted by the MLR are shown in Fig. 7 (zonal mean zonal winds are also plotted in Fig. 7a with green lines). The lower stratospheric tropical warming occurs during a period when the stratospheric subtropical westerly winds develop, in JulyAugust in the SH and in November-December in the NH. A tropospheric warming in mid-latitudes occurs in SeptemberOctober in the $\mathrm{SH}$ and in January-February in the $\mathrm{NH}$, and is associated with the downward penetration of westerly zonal mean zonal wind anomalies from the stratosphere (Fig. 6). The differences in the latitudinal structure of surface solar signals in Fig. 3 are consistent with the differences in the 
$z$ (a)Solarcoefficient T1000 (DJF)

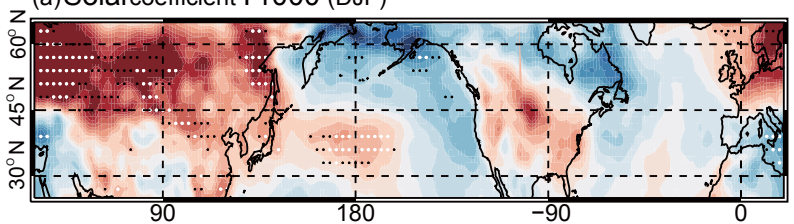

(b) Solarcoefficient T1000 (MAM)

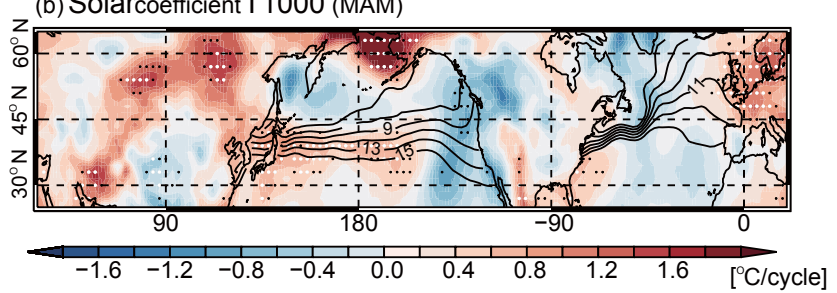

(c) SST climatology (MAM)

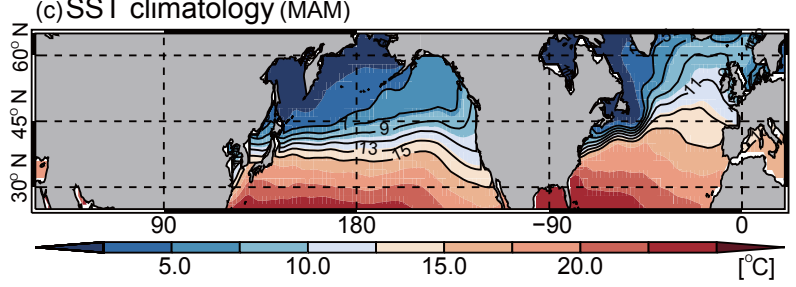

Figure 8. (a and b) Solar regression coefficient of the surface temperature (at $1000 \mathrm{hPa}$ ) over the $\mathrm{NH}$ mid-latitudes for (a) DJF and (b) MAM. Isothermal lines over oceans in (b) represent climatological SSTs displayed in the bottom panel. (c) Climatological mean SST in spring (MAM). Stippled areas with black and white dots indicate statistical significance at the 90 and $95 \%$ level, respectively.

downward penetration in the two hemispheres: downward penetration occurs through a modulation of the polar-night jet in the NH that projects onto the NAM, but a modulation of the subtropical jet in the SH does not project onto the SAM.

\subsection{Interactions with the ocean}

The role of the ocean as heat storage can be seen as persistent surface temperature anomalies from winter to spring. In addition, ocean currents advect SST anomalies to higher latitudes, which may introduce further delayed response. The evolution from winter to spring of the solar signals in surface temperatures in the mid-latitudes of the $\mathrm{NH}$ is illustrated in Fig. 8a and b, respectively. In winter, stratospheric zonal mean zonal wind anomalies extend from the stratosphere to the troposphere, and lead to a seesaw pattern between the polar region and mid-latitudes, similar to the NAM as shown in Fig. 3. In spring, stratospheric circulation anomalies associated with the polar-night jet start vanishing. This coincides with a weakening of the temperature anomalies over the continents. Conversely, temperature anomalies over the ocean basins east of the continents not only persist from winter, but also continue to develop. The positive temperature anomalies over the North Pacific, east of Japan, extend along $40^{\circ} \mathrm{N}$. In the Atlantic sector, positive temperature anoma- (a) 1979-2010 Solar coefficientERSST (DJF)
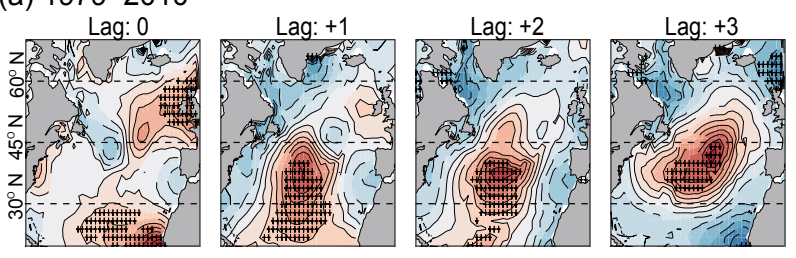

(b) 1880-2010

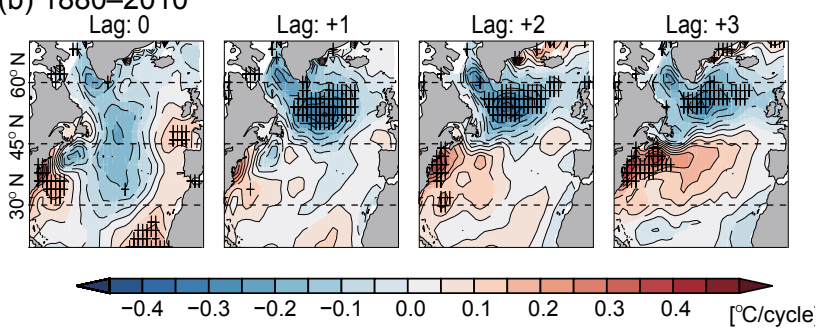

Figure 9. Solar regression coefficients of winter mean SST in the North Atlantic sector extracted from ERSST at lag times of 0, 1, 2 and 3 years, for (a) 1979 to 2010 and (b) 1880 to 2010. Stippled areas indicate statistical significance at the $90 \%$ level.

lies are located at lower latitudes along the southeastern US coastal region. A similar SST response in spring has been confirmed with a longer historical SST dataset from 1882 to 2008 (see Fig. 4 of Tung and Zhou, 2010). Note that temperature anomalies in the Pacific sector are found around ocean frontal zones, where meridional temperature gradients are strong (Fig. 8c), but in the Atlantic sector, temperature anomalies are located at lower latitudes.

As noted by Zhou and Tang (2010), mid-latitudes of the Northwestern Atlantic are cold during periods of high solar activity. However, positive SST anomalies located in the subtropics of the Atlantic sector in the eastern America shift gradually northward with time. Lagged solar signals in the SSTs are show in Fig. 9 for (a) modern and (b) historical periods. In both cases, when SST anomalies reach the sub-Arctic frontal zone (around $45^{\circ} \mathrm{N}$ ) with a 2-3-year lag, a meridional dipole pattern similar to the NAO develops (Gray et al., 2013; Scaife et al., 2013; Andrews et al., 2015; Thiéblemont et al., 2015). Although the cooling at mid-latitudes appears less pronounced in the modern era, the northward shift of positive anomalies associated with the solar cycle over the North Atlantic remains unchanged.

\subsection{Tropical solar signals}

Figure 10 shows the tropical part of the solar signal in SSTs extracted from the global picture in Fig. 1a. As mentioned previously, this pattern is characterized by a cooling over the eastern Pacific and the Atlantic in the SH and a warming in the central Pacific. To identify the characteristics of the spatial structure of these variations, an empirical orthogonal function (EOF) analysis is conducted on the SSTs over 
(a) Annual mean SST CMD

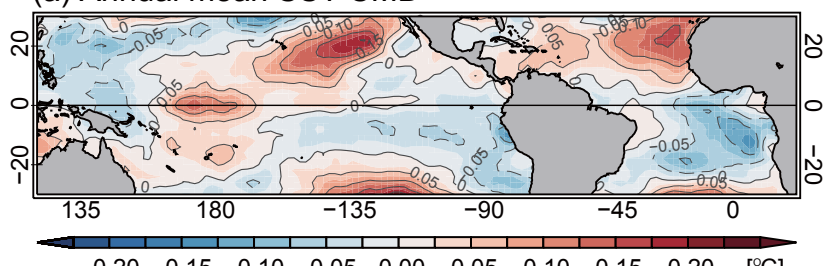

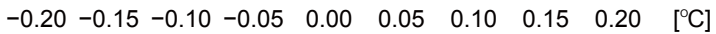

(b) EOF 3 , Sep-Feb

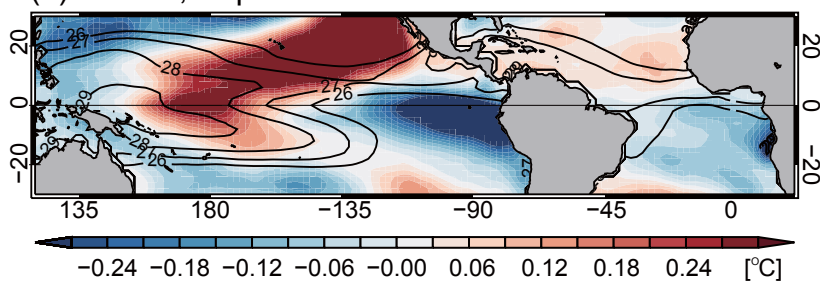

Figure 10. (a) Same as Fig. 1a, except for the tropical Pacific and Atlantic sectors only $\left(30^{\circ} \mathrm{S}-30^{\circ} \mathrm{N}, 120-20^{\circ} \mathrm{E}\right)$. (b) SST spatial structure of the third EOF in September-February for the period 1880-2010 (colour shading). Contours indicate climatological SST.

the tropical Pacific and the Atlantic sectors during September through February when ENSO shows the greatest persistence (Wolter and Timlin, 2011). The leading and the second EOFs represent canonical ENSO and secular trends, respectively. The third EOF shows decadal variations, and its spatial pattern is illustrated in Fig. 10b. The solar signal (Fig. 10a) agrees well with the spatial structure of EOF3, which is characterized by a cooling over the cold tongue regions and a warming over the warm pool region in the central Pacific. This pattern of tropical SSTs, known as El Niño Modoki, has been extracted as EOF2 with a shorter dataset from 1979 through 2004 (Fig. 2b in Ashok et al., 2007). Unlike a canonical ENSO, there is a substantial meridional asymmetry in the SST field such that there is warming in the $\mathrm{NH}$ and cooling in the $\mathrm{SH}$ in EOF3 as well as in the solar signal. Note that the solar signal has greater spatial extent, from the Pacific to Atlantic sectors, while that of EOF3 is confined mainly to the Pacific sector.

Cold tongues in tropical SSTs develop during boreal summer due to the Asian monsoon circulation (Wang, 1994). Therefore, the solar influence in the tropics is investigated for this season. Figure 11 shows correlation coefficients for boreal summer (JJA) between the solar index and (a) SSTs, (c) meridional wind velocity at $925 \mathrm{hPa}$ and (e) outgoing longwave radiation (OLR). Summertime climatologies are also displayed below the respective correlation plots; Fig. 11b depicts climatological SSTs (contours) and their deviation from the zonal mean SST (colour shading). The climatological northward component of the wind velocity at $925 \mathrm{hPa}$ is displayed with $2 \mathrm{~m} \mathrm{~s}^{-1}$ contours (Fig. 11d). Figure 11e shows climatological OLR (colour shading). Regions of negative solar SST signals (Fig. 11a) roughly coincide with

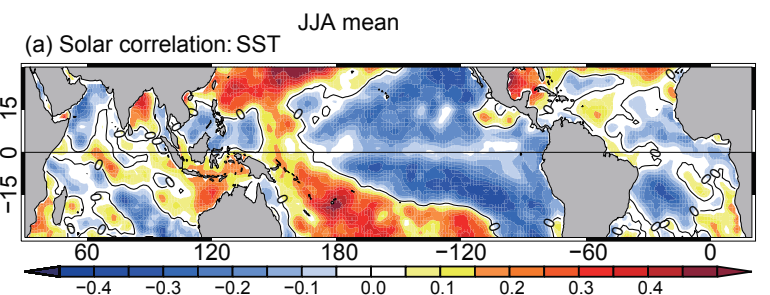

(b) Climatology: SST and deviation from zonal mean (JJA)

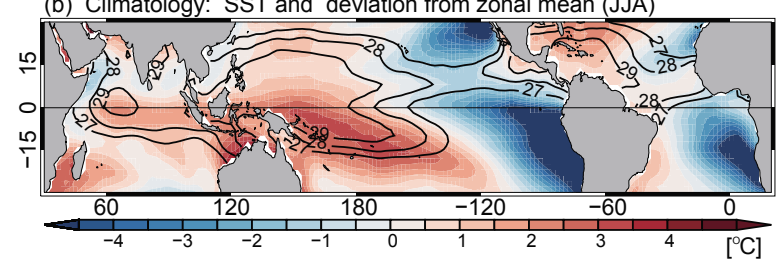

(c) Solar correlation: V925

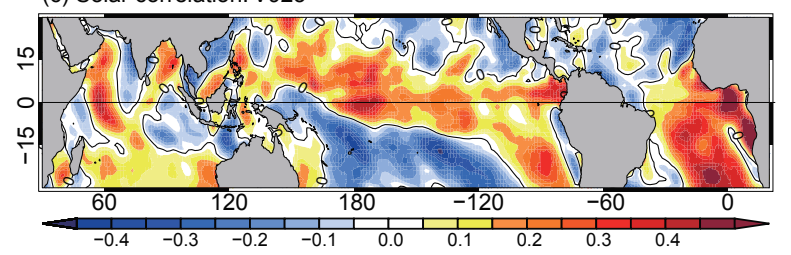

(d) Climatology: V925

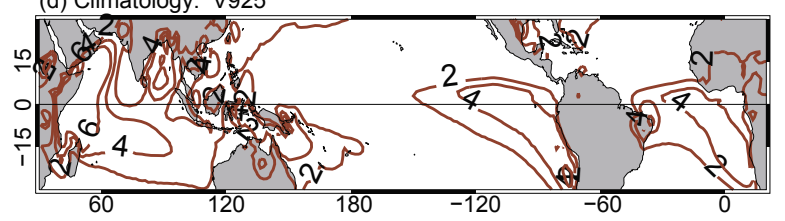

(e) Solar correlation: OLR
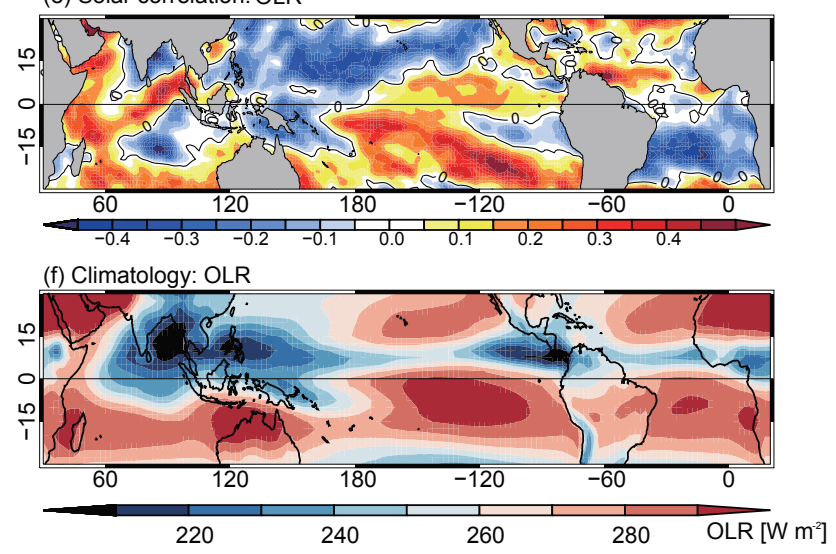

Figure 11. Boreal summer (JJA) solar signal in (a) SST, (c) meridional winds at $925 \mathrm{hPa}$ and (e) OLR, presented as correlations with the solar index for the period 1979-2010. (b) JJA mean climatological SST, with contours for 27,28 and $29^{\circ} \mathrm{C}$, and colour shading denoting the deviation from the latitudinal mean SST. (d) Climatological JJA northward wind component at $925 \mathrm{hPa}$ (contours every $2 \mathrm{~m} \mathrm{~s}^{-1}$ ). (f) Climatological JJA OLR (colour shading).

regions of low climatological SST with respect to the zonal mean, such as in the southeastern Pacific, the South Atlantic and the coastal Arabian Sea. These sectors are also characterized by strong cross-equatorial winds along the conti- 
nents (Fig. 11d). During periods of high solar activity a consistent increase in northward wind occurs in these regions (Fig. 11c). The correlation coefficients between the solar index (F10.7) and the OLR do not show a uniform increase of convective activity in the monsoon regions (lower OLR regions in Fig. 11f). The convective activity around the equatorial $\mathrm{NH}\left(0-10^{\circ} \mathrm{N}\right)$, such as over the Indian Ocean, South America and Africa, is suppressed, while the convective activity of the off-equatorial $\mathrm{NH}\left(15-20^{\circ} \mathrm{N}\right)$ in the Asian sector tends to be enhanced. Thus, the tropical solar influence is not characterized by a strengthening of the global monsoon circulation, but rather a northward shift of the convergence zone or the ascending branch of the Hadley circulation. This shift also introduces longitudinal structure in the SSTs due to the asymmetric distribution of the continents.

\section{Stratosphere-troposphere dynamical coupling processes}

The results of the observational analysis so far suggest that the surface solar signals in both the tropics and the extratropics are related to the stratosphere through changes in the stratospheric westerly jet. Because of strong and complex feedbacks inherent in the atmosphere-ocean system, it is not easy to understand from observations alone how stratospheric circulation changes globally affect the troposphere.

Therefore, we now compare the observed surface solar signals with the response obtained from an idealized coupled atmosphere-ocean model experiment. In this experiment (Yukimoto and Kodera, 2007), stratospheric zonal winds are forced by the addition of zonal angular momentum in the winter stratosphere at levels above $100 \mathrm{hPa}$ in the Meteorological Research Institute (MRI) coupled atmosphere-ocean general circulation model (MRI-CGCM2.3) (Yukimoto et al., 2006). The momentum forcing is essentially the same as that used by Thuburn and Craig (2000) except that the momentum forcing $\left(F_{\mathrm{m}}\right)$ is applied only in the winter hemisphere with seasonal variations, as follows.

$F_{\mathrm{m}}=A_{0} f(p)(\sin 2 \varphi)^{2} \operatorname{MAX}\left\{0, \cos \left[2 \pi\left(n-n_{0}\right) / 365\right]\right\}$,

with $A_{0}$ the maximum amplitude $\left(5 \mathrm{~m} \mathrm{~s}^{-1}\right.$ day $\left.^{-1}\right), n$ the day of the year and $n_{0}$ the central day of the winter (15 January in the $\mathrm{NH}$ and 15 July in the $\mathrm{SH})$. The vertical profile $f(p)$ is expressed as

$$
\begin{aligned}
f(p) & =1 & & p<10 \\
& =\ln (p / 100) / \ln (0.1) & & 10<p<100 \\
& =0 & & p>100,
\end{aligned}
$$

where $p$ denotes the pressure (hPa) and $\varphi$ denotes the latitude (radian).

Figure 12 shows the differences between the eastward and westward momentum (or strong and weak stratospheric westerly jet) experiments. Left- and right-hand panels are for
July and January means of the last 50 years of a 100 -year integration. A strong or weak stratospheric westerly jet in winters of extended period may exaggerate long-term feedback from the ocean, but we can see the effect of ocean more conspicuously. The momentum forcing and zonal mean zonal wind responses are shown in Fig. 12a and b. Although the momentum forcings are centred on $45^{\circ}$ latitude in both hemispheres, the response in zonal mean zonal winds differs in austral and boreal winters. A strengthening of the polar-night jet occurs in January, approximately poleward of $30^{\circ} \mathrm{N}$ in the $\mathrm{NH}$, and zonal mean zonal winds in the $\mathrm{NH}$ tropics decrease (denoted by "E" at the top of Fig. 12b). The deceleration occurs despite additional acceleration from the momentum forcing, due to the interaction with planetary waves. In contrast, in the SH in July, westerly winds weaken in the polar region.

Because stronger stratospheric westerly winds extend farther to lower latitudes in austral winter, a suppression of the ascending motion occurs more strongly in July in the tropics (Fig. 12c). As a consequence, stronger warming occurs around the tropical tropopause regions in July (Fig. 12d). Previous model studies (Thuburn and Craig, 2000; Kodera et al., 2011) showed that changes in stratospheric meridional circulation affect tropical convective activity through changes in static stability in the tropical tropopause region (Eguchi et al., 2015). In the present experiments also, suppression of equatorial ascending motion occurs in the troposphere in connection with the reduction of stratospheric mean meridional circulation change, as can be seen in the residual circulation differences in Fig. 12c. The extension of extratropical zonal mean zonal wind anomalies from the stratosphere to the troposphere occurs in association with a change in tropospheric wave activity as indicated by the Eliassen-Palm (E-P) flux (Fig. 12e). Upward-propagating waves are deflected equatorward around the tropopause region $(300 \mathrm{hPa})$, and produce easterly zonal mean zonal wind anomalies in the subtropics, forming a pair of easterly and westerly zonal mean zonal wind anomalies at higher latitudes (Fig. 12b). This anomalous zonal mean zonal wind pattern also creates anomalous tropospheric warming around 40$45^{\circ} \mathrm{N}$ through the thermal wind balance (Fig. 12d). A particularly interesting response is found in the summer troposphere. Although no external forcing is applied in the summer hemisphere, an anomalous mid-latitude warming and wave activity persist in the troposphere, in particular in the $\mathrm{SH}$. In fact, this latitudinal zone corresponds to the ocean frontal zone.

Figure 13a shows the horizontal structure of the annual mean SST differences between the stronger and weaker stratospheric westerly jet experiments, as in Fig. 12. This figure can be compared with the differences between high and low solar activity. The colour shading in Fig. 13a shows the difference normalized by the standard deviation. Anomalous SST warming occurs around $40^{\circ}$ latitude in both hemispheres, similar to the mid-latitude warming from the obser- 

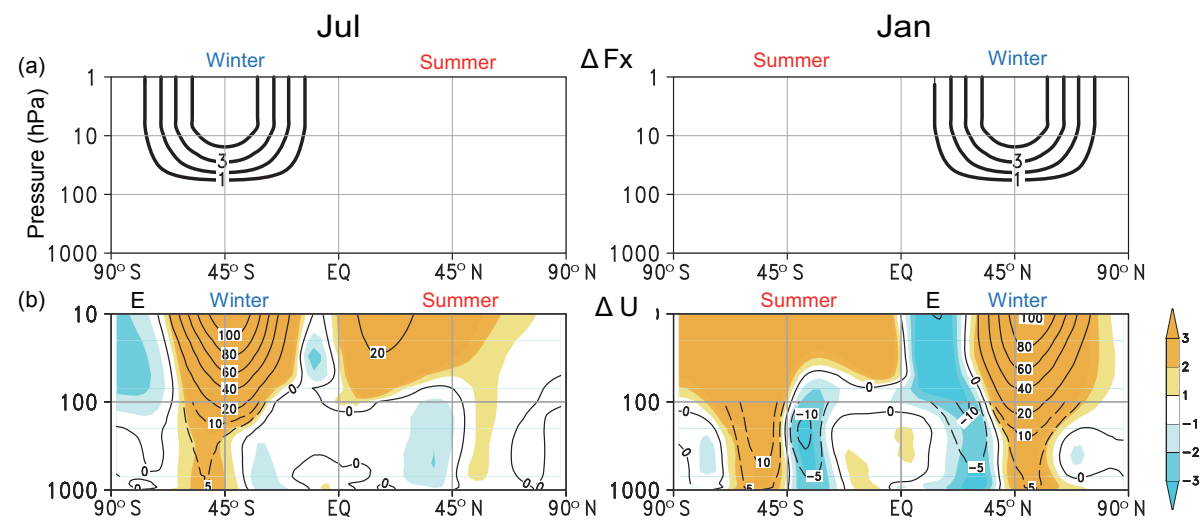

(c)

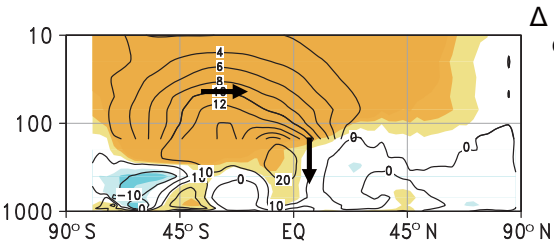

$\Delta$ residu
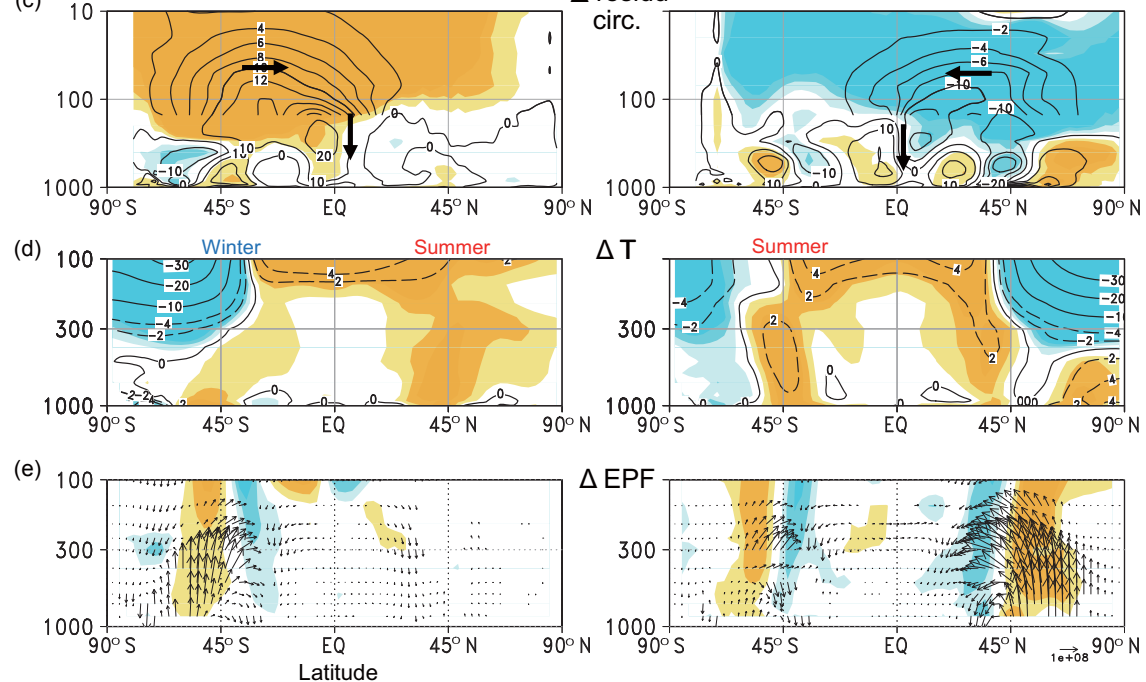

Figure 12. Difference between strong and weak stratospheric westerly jet experiments by Yukimoto and Kodera (2007) in July (left) and January (right): (a) zonal momentum forcing $\left(\mathrm{m} \mathrm{s}^{-1} \mathrm{day}^{-1}\right)$, (b) zonal mean zonal winds $\left(\mathrm{m} \mathrm{s}^{-1}\right)$, (c) mean meridional residual circulation $\left(10^{9} \mathrm{~kg} \mathrm{~s}^{-1}\right)$, (d) zonal mean air temperature $(\mathrm{K})$ and (e) E-P fluxes $\left(\mathrm{m}^{-2} \mathrm{~s}^{-2}\right.$ ) (arrows) and their divergence (colour shading). Colour shading indicates differences normalized by the standard deviation.

vations in response to the solar cycle in Fig. 1b. Cooling is also found in the equatorial southeastern Pacific and the Atlantic along the west coast of Africa, although it is quite small in the latter region. Note that the small response in the tropical Atlantic may be attributed to model deficiencies in lowlevel cloud formation. The cooling can be attributed to an increase of the cross-equatorial flow due to a suppression of rainfall near the equator, but an increase in off-equatorial regions (Fig. 13b). Cooling also appears in the coastal Arabian Sea in July (Fig. 13c) in connection with a strong northward meridional wind induced by an intensified Indian continent monsoon (Kodera, 2004). The increased convergence around the Indian continent is consistent with warming in the Bay of Bengal. These characteristics of the surface response to stratospheric westerly zonal wind changes are qualitatively consistent with the global surface solar signals from observations (Fig. 1).

\section{Centennial-scale variation}

It is generally believed that changes in the solar UV produce regional effects in the troposphere, but have little impact on global mean temperatures (e.g. IPCC, 2013). However, this is not completely true for centennial solar variations. The effect of long-lasting weaker stratospheric polar vortices on tropospheric climate can be seen in the numerical experiment presented above. Figure 14 shows annual mean surface air temperature differences between weak and strong stratospheric westerly polar-night jet experiments averaged over the last 50 years, as in Fig. 13. Note that the results of this experiment are more comparable with an extended period of extreme solar minimum (Maunder Minimum-like) conditions. The Earth's surface cools down remarkably. Global mean temperature decreases by about $0.5 \mathrm{~K}$, although total solar irradiance is unchanged. This global cooling is originally caused by the weakening of the stratospheric polar vortex, which in- 

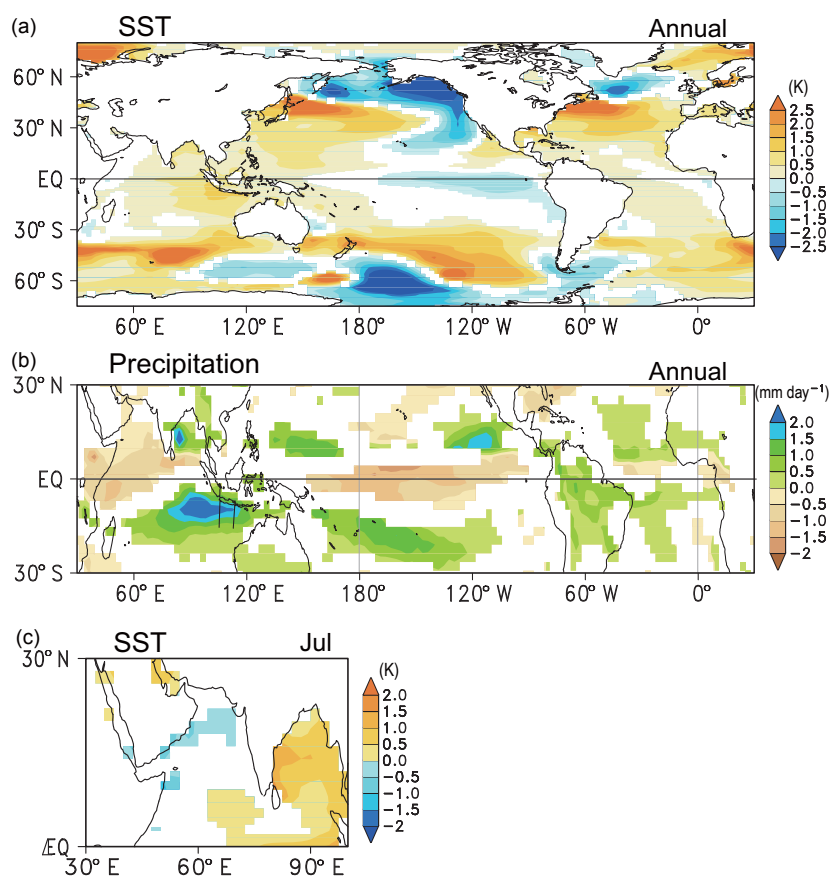

Figure 13. (a) Differences in the annual mean SST between strong and weak stratospheric westerly jet experiments, similar to Fig. 11. (b) Same as (a), except for the annual mean precipitation. (c) Same as (a), except for July mean SST in the Indian Ocean sector. Units are (a) $\mathrm{K}$, (b) $\mathrm{mm} \mathrm{day}^{-1}$ and (c) $\mathrm{K}$. Colour shading indicates regions where statistical significance exceeds the $95 \%$ level.

duces more frequent cold surges resulting in a larger snow cover extent in mid-latitudes. As a consequence, the Earth's albedo increases and the radiative balance changes without change in the TSI. The spatial structure of the temperature anomaly thus obtained is quite similar to that estimated from proxy data (see Fig. 3 in Shindell et al., 2001): a cooling over eastern Canada, eastern Europe to Russia and northeast Asia, as well as a warming over the west coast of North America, the west of Greenland and Kamchatka, although the warming of the Middle East is shifted a little southwestward. This very good agreement of the global spatial structure of the surface temperature changes suggests a dynamical origin of the cooling during the late Maunder Minimum period. This is consistent with the conclusion of Mann et al. (2009), that the temperature variations of the Little Ice Age and the Medieval Climate Anomaly are of dynamical origin. Thus, centennialscale solar signals could also be explained by a change in the spectral distribution of solar irradiance, with changes only in the UV part of the solar spectrum, even if the change in total energy was negligibly small.

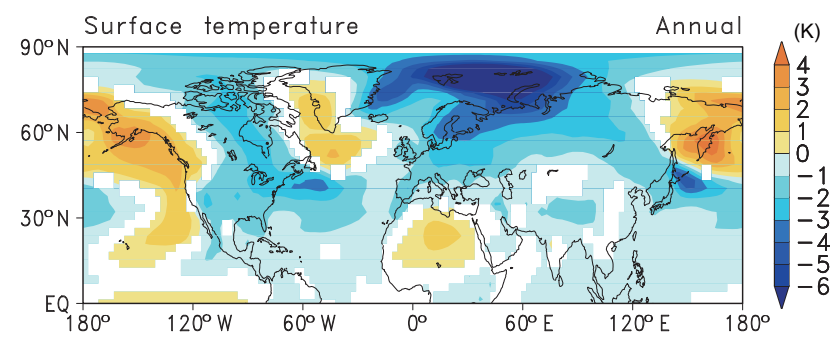

Figure 14. Similar to Fig. 13, except for annual mean surface temperature differences between weak and strong stratospheric westerly jet experiments, comparable to an extended period of extreme solar minimum (Maunder Minimum-like) conditions. Colour shading indicates regions where statistical significance exceeds the $95 \%$ level.

\section{Discussion and summary}

\subsection{Tropospheric processes}

Annual mean surface temperature variation related to the solar cycle has been studied by several authors using long historical data as indicated in the Introduction. In spite of different methods of analysis, the results present many similarities. The studies, however, focused on specific regions. Lohmann et al. (2004) indicate that significant solar signals are located in the Pacific sector, while Lean and Rind (2008) notice zonal warming signal along around $40^{\circ}$ latitudes in both hemispheres. ZT2010 describe solar signal in each oceanic basin: in the tropical Atlantic, the SST anomalies are cold south of the Equator during periods of high solar activity, but warm directly north of it. The northwestern Atlantic SST anomalies are cold, while those of the northwestern Pacific are warm except off the west coast of North America. The tropical eastern Pacific SST anomalies are cold, with exception of a thin warming band over the equatorial Pacific. The Indian Ocean shows warm anomalies. Gray et al. (2013) focus on lagged solar signal in the North Atlantic where NAOlike signal maximizes with a delay of about 3 years. They also report simultaneous solar signal such as weak cooling in the equatorial eastern Pacific, warming in northwest Pacific and a band of weak warming around $50-60^{\circ} \mathrm{S}$. These solar signals reported by previous studies and described above can be found in Fig. 1, except for the warming around 50 $60^{\circ} \mathrm{S}$. In fact, although less significant, larger warmings can also be recognized in the result of Gray et al. (2013) around $40^{\circ} \mathrm{S}$ latitude west of South America and Australia, similar to the present study and others. As for the origin of these surface solar signals, Lean and Rind (2008) consider an involvement of the large-scale dynamical circulation of the atmosphere. ZT2010 consider dynamical response involving ocean-atmosphere couplings over the Pacific and Atlantic oceans, but they attribute the direct solar heating effect to the uniform warming of the small-scale Indian Ocean. In these studies, no consideration is made, however, about concrete 
atmospheric processes that may induce solar signals in different regions.

In order to understand the physical processes, we first characterized positive and negative solar signals distributed over the globe. The mid-latitude warming during high solar activity periods in the northwestern Pacific and that of the Southern Ocean around $40^{\circ}$ latitudes are, in fact, located in the oceanic frontal zone as illustrated in Fig. 1. Negative SST anomalies in the tropical SH eastern Pacific and the Atlantic are formed in the cold tongue regions. Therefore, we may be able to group the solar signals in surface temperature as follows:

1. mid-latitude warming around the ocean frontal zones

2. cooling in the tropical cold tongue regions.

In addition, warming over the subpolar Eurasian continent and cooling in the west of Greenland can be attributed as solar signals related to the planetary wave structure (Fig. 3). Warming is also found over Antarctica with reanalysis data, which needs to be verified with more direct observational data. The observed feature in the SSTs in Fig. 1 is well reproduced in the results of the numerical experiment in Fig. 13, which show a difference between two 50-year means of strong and weak stratospheric westerly jet conditions. The mid-latitude warming in the northwestern Atlantic sector in the model appears together with the northwestern Pacific sector because of the sufficient time for the response.

\subsubsection{Oceanic frontal zone}

The tropospheric parts of Figs. 5, 6 and 7 are combined in Fig. 15 to illustrate the process suggested to produce tropospheric solar signal. The tropospheric temperature signal is associated with a downward penetration of zonal wind anomalies. Note that the statistical significance is higher in the zonal wind field than that of temperature (Fig. 15). A pair of warming and cooling is formed at both sides of the axis of the zonal mean zonal wind anomaly consistent with the thermal wind relationship. Westerly jet and ocean interaction is especially strong around the baroclinic zone, where meridional temperature gradient is large. The numerical experiment by Nakamura et al. (2008) suggests an important role of oceanic frontal zones in creating variability in the tropospheric westerly winds through modifications of baroclinic waves. The impact of the momentum forcing experiment of stratospheric westerly jet also produces warmings around the baroclinic zone in the $\mathrm{NH}$ as well as in the $\mathrm{SH}$ (Fig. 13); anomalous mid-latitude warming and wave activity persist in the troposphere, during the summer, although no external forcing is applied. Thus, anomalous temperatures in the baroclinic zone are maintained throughout the year, which could be the reason for the significant and persistent solar signal in the annual mean temperature field. The possible role of ocean feedback in enhancing stratospheric impact
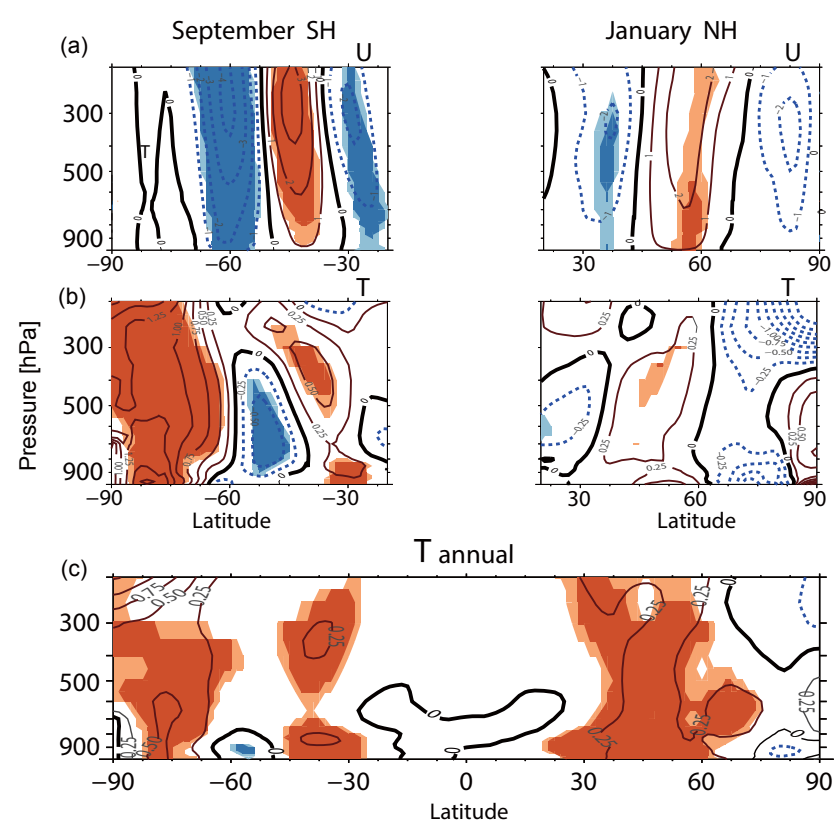

Figure 15. (a) Same monthly solar regression coefficient of zonal mean zonal winds as in Fig. 6, except for the tropospheric part: (left) $\mathrm{SH}$ in September, and (right) $\mathrm{NH}$ in January. (b) Same as in (a), except for the temperature signal in Fig. 7. (c) Tropospheric part of solar regression coefficients of the annual zonal mean air temperature in Fig. 5a. Contour intervals are $0.25 \mathrm{~K}$ for temperature and $1 \mathrm{~m} \mathrm{~s}^{-1}$ for wind.

is also discussed in Yukimoto and Kodera (2007) and Misios and Schmidt (2013).

As reported by ZT2010, solar signal in the mid-latitudes of the North Pacific and North Atlantic are different. Cooling anomalies in the Atlantic sector are replaced by warm anomalies with a delay of about 3 years (Gray et al., 2013; Andrews et al., 2015). Scaife et al. (2013) demonstrated the role of ocean heat content producing this delayed effect. However, their calculated delays from a mechanistic model are too small to explain the observed signals. In the following, we suggest an additional mechanism, which may lead to the delayed response in the Atlantic sector. During high solar activity, anomalous warmings develop over both Pacific and Atlantic sectors. However, the latitudinal positions of these warming anomalies are different between the Pacific and Atlantic sectors due to the structure of the stationary planetary waves; in the Pacific, warming occurs around the frontal region, whereas that in the Atlantic occurs in the subtropics, i.e. far south of the frontal zone as indicated in Fig. 8b. Warm anomalies in Atlantic sector subsequently shift northward to reach the frontal zone in 2 to 3 years (Fig. 9). The development of an NAO-like solar signal could be expected around the ocean frontal zone through positive feedback between the baroclinic waves and SSTs (see supplementary Fig. 2 in Thiéblemont et al., 2015). In this respect, it is important to differentiate the spatial structures of the NAO 
and AO (Kodera and Kuroda, 2004; D. Wang et al., 2005); $\mathrm{NAO}$ is a regional meridional dipole pattern over the North Atlantic due to interaction between the zonal wind and transient eddies, whereas the $\mathrm{AO}$ involves changes in planetary waves and polar vortex. The transformation of the solar signal from AO-like to NAO-like in 3 years, such as simulated in a coupled ocean chemistry-climate model experiment (Supplementary Fig. 3 of Thiéblemont et al., 2015), could be interpreted this way.

\subsubsection{Cold tongue region}

Van Loon et al. (2007) and Meehl et al. (2008, 2009) suggested that the tropospheric solar influence originates from an amplification by atmosphere-ocean interaction in the tropical Pacific, i.e., a modulation of the ENSO cycle. However, cooling anomalies during high solar activity do not solely occur in the Pacific tropical cold tongue regions, but in the Atlantic as well. ZT2010 note also that the cooling in the Atlantic sector of the tropical SH is accompanied by a warming northward of the equator. The tropical Atlantic Ocean has no self-sustaining oscillation mode, unlike the tropical Pacific, but it can respond to external forcing with a northsouth SST seesaw through the interaction of wind, evaporation and SST (Xie and Tanimoto, 1998). Such a dipole pattern is discernible in Fig. 10. In fact, variations with the solar cycle of tropical Atlantic SSTs associated with crossequatorial meridional winds have already been reported (Lim et al., 2006; Suh and Lim, 2006). Thus, the solar signal characterized by a simultaneous cooling in the two cold tongue regions could be understood from a northward shift of the convergence zone (i.e., the ascending branch of the Hadley cell) during boreal summer. Stronger southeasterly winds produce cooling in the equatorial SH west of the continents. These anomalies develop and are maintained through windevaporation-SST (WES) feedback, similar to that which creates a northward-displaced intertropical convergence zone in the climatological state (Xie, 2004).

Figure 16 summarizes troposphere atmospheric processes associated with the prominent solar signals on the Earth's surface: (i) changes in westerlies associated with anomalous warming equatorward of the central location of anomalous westerlies and (ii) northward shift of the tropical convergence zone associated with cooling west of the South American and African continents through modulation of cross-equatorial flow.

\subsection{Connection with the stratosphere}

The question now is as follows: how can the tropospheric circulation changes, as illustrated in Fig. 16, be associated with the solar cycle? It is evident that decreased cloud coverage due to fewer cosmic rays during high solar activity cannot explain such a cooling over the cold tongue regions, where low-level clouds usually form (Kristjánsson et al., 2004). In the case of direct solar impact on the Earth's surface through visible light, one should expect a warming of the tropics similar to that observed in climatological SST distribution in Fig. 2e. For this, it needs to explain why warmings related with the 11-year solar cycle appear rather in mid-latitudes (Figs. 2d and 5a).

We suggest that several aspects of the solar signal on the Earth's surface described in our study may be explained by solar UV heating changes in the upper stratosphere, which penetrate to the troposphere through two pathways: the stratospheric westerly jet in the extratropics, and the stratospheric mean meridional circulation in the tropics, as suggested by Kodera and Kuroda (2002). The mid-latitude warming on the Earth's surface through the solar signal can be understood as produced in association with the downward penetration of zonal mean zonal wind anomalies from the upper stratosphere during winter to spring in both hemispheres (Fig. 6). Connection in the tropics through changes in vertical velocity is suggested to occur through changes in tropical lower stratospheric temperature (see Fig. 1 of Kodera and Shibata, 2006). Tropical lower stratospheric temperature change associated with the solar cycle is larger in boreal summer (July-August) than that in austral summer (NovemberDecember), as can be seen in Fig. 7 of Labitzke (2001). Tropical cooling associated with the solar cycle develops during summer to autumn following the increase of cross-equatorial flow in boreal summer. It is difficult to investigate how the lower stratospheric temperature affects the tropical convective activity for solar-cycle-scale variation based on observational data only, however. In this respect, the results of our momentum experiments suggest that the change in the $\mathrm{BD}$ circulation in the stratosphere can be connected to the raising branch of the Hadley circulation and modulate upward velocity in the tropics (Fig. 11).

There are some differences in solar signals between the $\mathrm{NH}$ and SH both in the stratosphere and troposphere, which also need to be explained. To emphasize the initial role of the solar UV heating in the upper stratosphere, only the early winter situation was shown in Fig. 15 of Kodera and Kuroda (2002). However, the stratospheric circulation evolves seasonally from a radiatively controlled to a dynamically controlled state. Here, we show these two stages schematically in Fig. 17 based on previous studies (Kodera and Kuroda, 2002; Matthes et al., 2006, 2013). Increased solar UV heating in the tropics only produces a small increase in the subtropical jet in the case of no interaction with waves (Fig. 17a). However, such a small initial effect can be amplified through wave-mean flow interactions. During early winter, when planetary wave forcing is small, the waves (green arrows) are deflected at the stratopause subtropical jet (Fig. 17b). In this case, the downward extension of the subtropical jet occurs in association with significant tropical warming and mid-latitude cooling (Fig. 17b) as shown in Kodera and Kuroda (2002). In contrast, when planetary wave forcing becomes large enough in late win- 


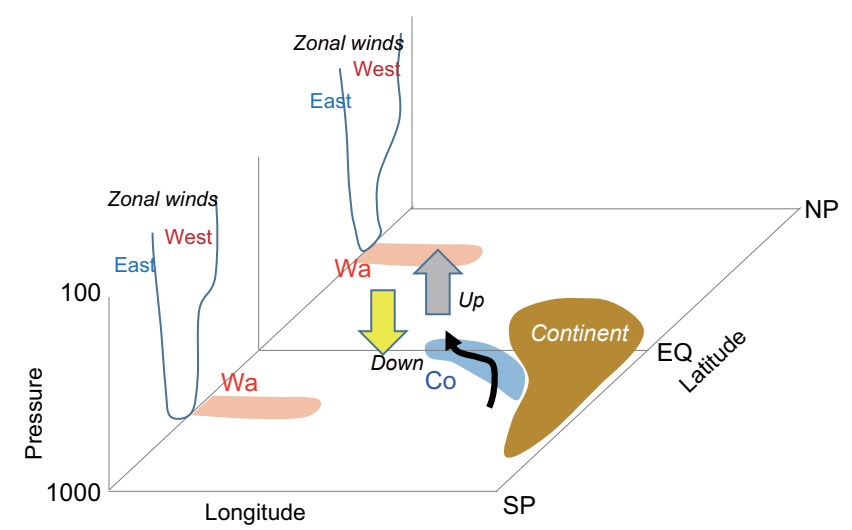

Figure 16. Schematic presentation of tropospheric processes related to the solar signals in the Earth's surface temperature: (i) changes in the westerly jet (west or east) produce anomalous warming (Wa) equatorward of the centre of anomalous westerlies. (ii) Northward shift of the tropical convergence zone (up and down) produces cooling $(\mathrm{Co})$ west of the continent through modulation of crossequatorial flow (arrow).

(a) Without interaction

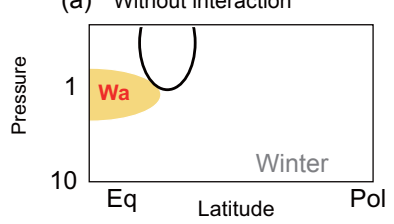

(b) Radiative control (early)

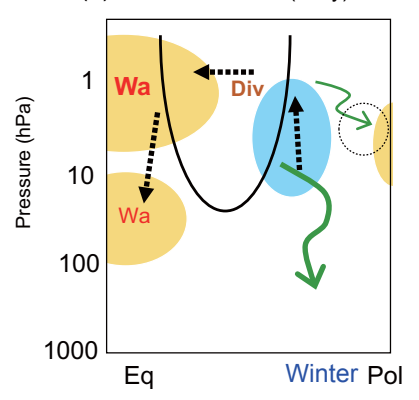

(c) Dynamical control (late)
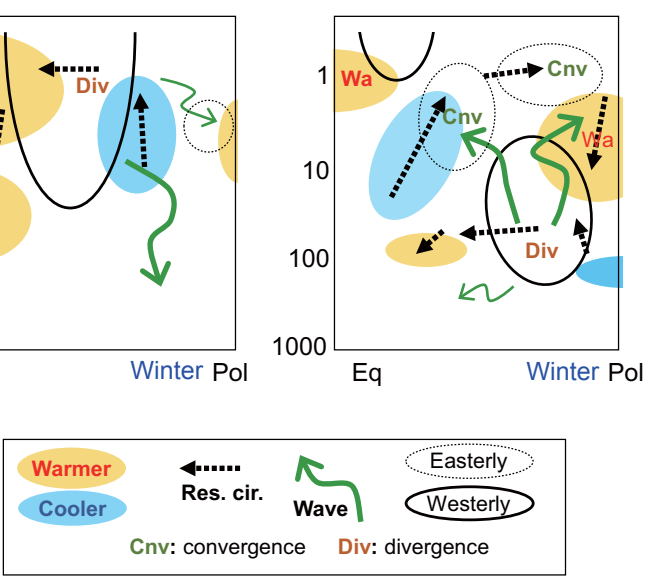

Figure 17. Schematic presentation of the solar influence on the winter stratosphere. (a) Hypothetical response to solar UV heating without interaction with planetary waves. (b) Early winter when solar radiative forcing dominates, and (c) late winter when dynamical forcing from the troposphere becomes more important. Solid (dashed) contours display anomalous westerly (easterly) winds. Yellow (blue) filled contours represent anomalous warming (cooling). Solid green (dashed black) arrows indicate anomalous propagation of planetary waves (mean residual circulation). "Div" and "Cnv" indicate anomalous divergence and convergence of the E-P flux, respectively. See text for details. ter to spring, the waves penetrate the subtropical upper stratosphere-stratopause region, leading to a poleward shift of the westerly jet (Dunkerton, 2000) (Fig. 17c). Enhanced vertical wave propagation along the polar-night jet results in an increased convergence of waves in the upper stratosphere, on the one hand, while on the other hand it induces divergence in the lower stratosphere, by which westerly anomalies descend into the polar region (Kuroda and Kodera, 1999). This results in a warming in the polar region of the upper stratosphere, but a cooling (or a reduction of the warming) in the tropical stratosphere due to an enhanced mean meridional circulation, as schematically illustrated in Fig. 17c. Thus, the differences in the solar signal characteristics between the $\mathrm{SH}$ and the $\mathrm{NH}$ can be understood by the different durations of the radiatively and dynamically controlled stages related to different planetary wave activity.

Lower stratospheric tropical heating was proposed as the possible origin of the solar influence on the troposphere (Haigh et al., 2005; Simpson et al., 2009). The solar signal in the NH is, in fact, transmitted from the upper stratosphere to the surface through a poleward-downward shift of anomalous zonal mean zonal wind, which creates a NAMlike structure in the troposphere. In the $\mathrm{SH}$, the planetary wave forcing is smaller, meaning that, climatologically, the radiatively controlled stage lasts longer than in the $\mathrm{NH}$. As a consequence, the stratopause subtropical jet develops and extends to lower levels without a large poleward shift, meaning in turn that tropospheric solar signals in the SH do not resemble the SAM, which is sensitive to the variability in the westerly jet in high latitudes. On the other hand, change in westerlies in lower latitudes produces larger solar signals in the tropical lower stratosphere.

The dynamical solar influence from the stratosphere can be reproduced by forcing stratospheric zonal mean winds in a coupled atmosphere-ocean general circulation model as shown in Figs. 11 and 12. A realistic numerical experiment with solar UV forcing in a general circulation model without an interactive ocean successfully reproduced the downward propagation of solar signals during $\mathrm{NH}$ winter (e.g. Matthes et al., 2006). More recent advanced middle atmosphere chemistry-climate models, including the feedback of the ocean, can now simulate zonal mean zonal wind variations with the solar cycle and their extension to the troposphere in both hemispheres, as well as the observed differences in the NH and the SH (see e.g. Figs. 10 and 11 of Hood et al., 2015). The fact that the realistic solar response is only obtained from the models capable of reproducing realistic upper stratospheric ozone variability also supports the downward penetration of the solar influence from the upper stratosphere.

It should finally be noted that centennial circulation changes produced in the stratosphere can affect global mean surface temperature through changes in the Earth's surface condition without changes in total solar irradiance. The following processes, however, need further clarification: (i) the 
role of ocean fronts and atmospheric baroclinic eddies in the downward extension of zonal mean zonal winds from the stratosphere, and (ii) the role of tropical convection in interactions between the stratospheric mean meridional circulation and the Hadley circulation. Concerning the La Niña-like SST anomaly, Roy and Haigh (2012) confirmed a tendency for La Niña to occur more frequently during the peak year of the solar cycle as previously suggested by van Loon et al. (2007). However, their peak year is only 1 year among 11 years of a solar cycle. The SST pattern related to the entire solar cycle extracted by CMD or MLR methods rather resembles El Niño Modoki of Ashok et al. (2007), as illustrated in Fig. 10. In fact, the La Niña-like pattern in the solar peak year rapidly evolves to a different pattern in 1 or 2 years (Meehl and Arblaster, 2009). Such non-linear aspects of the interaction between the ENSO and solar cycle will be addressed in a separate study.

\section{Data availability}

Meteorological reanalysis, historical datasets and indices used in this paper are all publicly available. NOAA Extended Reconstructed SST v3b (ERSST) is available at http://www. esrl.noaa.gov/psd/data/gridded/data.noaa.ersst.html (NOAA, 2016). The ERA-Interim dataset (ECMWF, 2016) is available at http://apps.ecmwf.int/datasets/ after registration. The $\mathrm{F} 10.7 \mathrm{~cm}$ solar radio flux dataset is available at http://lasp. colorado.edu/lisird/tss/noaa_radio_flux.html (LASP, 2016). Solar sunspot numbers are available at http://www.sidc. be/silso/datafiles (SIDC, 2016). Aerosol optical depths are available at http://data.giss.nasa.gov/modelforce/strataer/ tau.line_2012.12.txt (NASA, 2016). $\mathrm{CO}_{2}$ concentration dataset (UVIC, 2016) is available at http://climate.uvic.ca/ EMICAR5/forcing_data/RCP85_MIDYR_CONC.DAT.

Data from the model experiments are available on request by contacting Seiji Yukimoto (yukimoto@mri-jma.go.jp).

Codes to perform all the analysis are written in the Interactive Data Language programming language, and are available upon request by contacting Rémi Thiéblemont (remi.thieblemont@latmos.ipsl.fr).

Acknowledgements. This work was supported in part by JSPS Grants-in-Aid for Scientific Research (S)24224011 and (C)25340010. Katja Matthes and Rémi Thiéblemont acknowledge support from the Helmholtz University Young Investigators Group NATHAN, funded by the Helmholtz Association through the President's Initiative and Networking Fund, and the GEOMAR Helmholtz Centre for Ocean Research Kiel. This work has been conducted within the framework of the WCRP/SPARC SOLARISHEPPA activity.

Edited by: P. Haynes

Reviewed by: two anonymous referees

\section{References}

Andrews, M. B., Knight, J. R., and Gray, L. J.: A simulated lagged response of the North Atlantic Oscillation to the solar cycle over the period 1960-2009, Environ. Res. Lett., 10, 054022, doi:10.1088/1748-9326/10/5/054022, 2015.

Ashok, K., Behera, S. K., Rao, S. A., Weng, H., and Yamagata, T.: El Niño Modoki and its possible teleconnection, J. Geophys. Res., 112, C11007, doi:10.1029/2006JC003798, 2007.

Austin, J., Tourpali, K., Rozanov, E., Akiyoshi, H., Bekki, S., Bodeker, G., Brühl, C., Butchart, N., Chipperfield, M., Deushi, M., Fomichev, V. I., Giorgetta, M. A., Gray, L., Kodera, K., Lott, F., Manzini, E., Marsh, D., Matthes, K., Nagashima, T., Shibata, K., Stolarski, R. S., Struthers, H., and Tian, W.: Coupled chemistry climate model simulations of the solar cycle in ozone and temperature, J. Geophys. Res., 113, D11306, doi:10.1029/2007JD009391, 2008.

Baldwin, M. P. and Dunkerton, T. J.: The solar cycle and stratosphere-troposphere dynamical coupling, J. Atmos. Sol.Terr. Phy., 67, 71-82, 2005.

Blume, C., Matthes K., and Horenko I.: Supervised learning approaches to classify sudden stratospheric warming events, J. Atmos. Sci., 69, 1824-1840, 2012.

Brohan, P., Kennedy, J. J., Harris, I., Tett, S. F. B., and Jones, P. D.: Uncertainty estimates in regional and global observed temperature changes: a new dataset from 1850, J. Geophys. Res., 111, D12106, doi:10.1029/2005JD006548, 2006.

Chiodo, G., Marsh, D. R., Garcia-Herrera, R., Calvo, N., and García, J. A.: On the detection of the solar signal in the tropical stratosphere, Atmos. Chem. Phys., 14, 5251-5269, doi:10.5194/acp-14-5251-2014, 2014.

Dee, D. P., Uppala, S. M., Simmons, A. J., Berrisford, P., Poli, P., Kobayashi, S., Andrae, U., Balmaseda, M. A., Balsamo, G., Bauer, P., Bechtold, P., Beljaars, A. C. M., van de Berg, L., Bidlot, J., Bormann, N., Delsol, C., Dragani, R., Fuentes, M., Geer, A. J., Haimberger, L., Healy, S. B., Hersbach, H., Hólm, E. V., Isaksen, L., Kållberg, P., Köhler, M., Matricardi, M., McNally, A. P., Monge-Sanz, B. M., Morcrette, J.-J., Park, B.-K., Peubey, C., de Rosnay, P., Tavolato, C., Thépaut, J.-N., and Vitart, F.: The ERA-Interim reanalysis: configuration and performance of the data assimilation system, Q. J. Roy. Meteor. Soc., 137, 553-597, 2011.

Dunkerton, T. J.: Midwinter deceleration of the subtropical mesospheric jet and interannual variability of the high-latitude flow in UKMO analyses, J. Atmos. Sci., 57, 3838-3855, 2000.

ECMWF: ERA-Interim dataset, available at: http://apps.ecmwf.int/ datasets/, last access: 18 October 2016.

Eguchi, N., Kodera, K., and Nasuno, T.: A global non-hydrostatic model study of a downward coupling through the tropical tropopause layer during a stratospheric sudden warming, Atmos. Chem. Phys., 15, 297-304, doi:10.5194/acp-15-297-2015, 2015.

Frame, T. H. and Gray, L. J.: The 11-year solar cycle in ERA-40 data: An update to 2008, J. Climate, 23, 2213-2222, 2010.

Georgieva, K., Kirov, B., Tonev, P., Guineva, V., and Atanasov, D.: Long-term variations in the correlation between NAO and solar activity: The importance of north-south solar activity asymmetry for atmospheric circulation, Advances in Space Res., 40, 11521166, 2007. 
Gillett, N. P., Kell, T. D., and Jones P. D.: Regional climate impacts of the Southern Annular Mode, Geophys. Res. Lett., 33, L23704, doi:10.1029/2006GL027721, 2006.

Gray, L. J., Beer, J., Geller, M., Haigh, J. D., Lockwood, M., Matthes, K., Cubasch, U., Fleitmann, D., Harrison, G., Hood, L., Luterbacher, J., Meehl, G. A., Shindell, D., van Geel, B., and White, W.: Solar influence on climate, Rev. Geophys., 48, RG4001, doi:10.1029/2009RG000282, 2010.

Gray, L. J., Scaife, A. A., Mitchell, D. M., Osprey, S., Ineson, S., Hardiman, S., Butchart, N., Knight, J., Sutton, R., and Kodera, $\mathrm{K}$ : A lagged response to the 11 year solar cycle in observed winter Atlantic/European weather patterns, J. Geophys. Res., 118, 13405-13420, doi:10.1002/2013JD020062, 2013.

Haigh, J. D., Blackburn, M., and Day, R.: The response of tropospheric circulation to perturbations in lower-stratospheric temperature, J. Climate, 18, 3672-3685, doi:10.1175/JCLI3472.1, 2005.

Hood, L. L. and Soukharev, B. E.: The lower-stratospheric response to 11-yr solar forcing: Coupling to the troposphere-ocean response, J. Atmos. Sci., 69, 1841-1864, 2012.

Hood, L. L., Misios, S., Mitchell, D. M., Rozanov, E., Gray, L. J., Tourpali, K., Matthes, K., Schmidt, H., Chiodo, G., Thiéblemont, R., Shindell, D., and Krivolutsky, A.: Solar signals in CMIP-5 simulations: The ozone response, Q. J. Roy. Meteor. Soc., 141, 2670-2689, doi:10.1002/qj.2553, 2015.

IPCC: Climate Change 2013, The physical science basis: Summary for policymakers, Cambridge, UK, 2013.

Kaplan, A., Cane, M. A., Kushnir, Y., Clement, A. C., Blumenthal, M. B., and Rajagopalan, B.: Analyses of global sea surface temperature 1856-1991, J. Geophys. Res., 103, 18567-18589, 1998.

Kodera, K.: Solar influence on the Indian Ocean monsoon through dynamical processes, Geophys. Res. Lett., 31, L24209, doi:10.1029/2004GL020928, 2004.

Kodera, K. and Kuroda, Y.: Dynamical response to the solar cycle, J. Geophys. Res., 107, 4749, doi:10.1029/2002JD002224, 2002.

Kodera, K. and Kuroda Y.: Two teleconnection patterns involved in the North Atlantic/Arctic Oscillation, Geophys. Res. Lett., 31, L20201, doi:10.1029/2004GL020933, 2004.

Kodera, K. and Shibata, K.: Solar influence on the tropical stratosphere and troposphere in the northern summer, Geophys. Res. Lett., 33, L19704, doi:10.1029/2006GL026659, 2006.

Kodera, K., Mukougawa, H., and Kuroda, Y.: A general circulation model study of the impact of a stratospheric sudden warming event on tropical convection, SOLA, 7, 197-200, 2011.

Kopp, G. and Lean, J. L.: A new, lower value of total solar irradiance: Evidence and climate significance, Geophys. Res. Lett., 38, L01706, doi:10.1029/2010GL045777, 2011.

Kristjánsson, J. E., Kristiansen, J., and Kaas, E.: Solar activity, cosmic rays, clouds and climate - an update, Adv. Space Res., 34, 407-415, 2004.

Kuchar, A., Sacha, P., Miksovsky, J., and Pisoft, P.: The 11-year solar cycle in current reanalyses: a (non)linear attribution study of the middle atmosphere, Atmos. Chem. Phys., 15, 6879-6895, doi:10.5194/acp-15-6879-2015, 2015.

Kuroda, Y. and Kodera, K.: Role of planetary waves in the stratosphere-troposphere coupled variability in the northern hemisphere winter, Geophys. Res. Lett., 26, 2375-2378, 1999.

Kuroda, Y. and Kodera, K.: Effect of the solar cycle on the Polarnight jet oscillation, J. Meteorol. Soc. Jpn., 80, 973-984, 2002.
Labitzke, K.: The global signal of the 11-year sunspot cycle in the stratosphere: Differences between solar maxima and minima, Meteorol. Z., 10, 83-90, 2001

LASP: F10.7 cm solar radio flux dataset, available at: http://lasp. colorado.edu/lisird/tss/noaa_radio_flux.html, last access: 18 October 2016.

Lean, J. L., Beer, J., and Bradley, R.: Reconstruction of solar irradiance since 1610: implications for climate change, Geophys. Res. Lett., 23, 3195-3198, 1995.

Lean, J. L. and Rind, D. H.: How natural and anthropogenic influences alter global and regional surface temperatures: 1889 to 2006, Geophys. Res. Lett., 35, L18701, doi:10.1029/2008GL034864, 2008.

Legras, B., Mestre, O., Bard, E., and Yiou, P.: A critical look at solar-climate relationships from long temperature series, Clim. Past, 6, 745-758, doi:10.5194/cp-6-745-2010, 2010.

Lim, G.-H., Suh, Y.-C., and Kim, B.-M.: On the origin of the tropical Atlantic decadal oscillation based on the analysis of the ICOADS, Q. J. Roy. Meteor. Soc., 132, 1139-1152, 2006.

Lohmann, G., Rimbu, N., and Dima, M.: Climate signature of solar irradiance variations: Analysis of long-term instrumental, historical, and proxy data, Int. J. Climatol., 24, 1045-1056, doi:10.1002/joc.1054, 2004.

Lu, H., Gray, L. J., Jarvis, J., and Baldwin, M.: High and low frequency 11-year solar cycle signature in the Southern Hemispheric winter and spring, Q. J. Roy. Meteor. Soc., 137, 16411656, 2011.

Mann, M. E., Zhang, Z., Rutherford, S., Bradley, R. S., Hughes. M. K., Shindell, D., Ammann, C., Faluvegi, G., and Ni, F.: Global signatures and dynamical origins of the Little Ice Age and Medieval Climate Anomaly, Science, 326, 1256-1260, doi:10.1126/science.1177303, 2009.

Marsh, D. R. and Garcia, R. R.: Attribution of decadal variability in lower stratospheric tropical ozone, Geophys. Res. Lett., 34, L21807, doi:10.1029/2007GL030935, 2007.

Matthes, K., Kuroda, Y., Kodera, K., and Langematz, U.: Transfer of the solar signal from the stratosphere to the troposphere: Northern winter, J. Geophys. Res., 111, D06108, doi:10.1029/2005JD006283, 2006.

Matthes, K., Kodera, K., Garcia, R. R., Kuroda, Y., Marsh, D. R., and Labitzke, K.: The importance of time-varying forcing for QBO modulation of the atmospheric 11 year solar cycle signal, J. Geophys. Res.-Atmos., 118, 4435-4447, doi:10.1002/jgrd.50424, 2013.

Meehl, G. A. and Arblaster J. M.: A lagged warm event-like response to peaks in solar forcing in the Pacific region, J. Climate, 22, 3647-3660, 2009.

Meehl, G. A., Arblaster, J. M., Branstator, G., and van Loon, H.: A coupled air-sea response mechanism to solar forcing in the Pacific region, J. Climate, 21, 2883-2897, 2008.

Meehl, G. A., Arblaster, J. M., Matthes, K., Sassi, F., and van Loon, H.: Amplifying the Pacific climate system response to a small 11 year solar cycle forcing, Science, 325, 111-1118, doi:10.1126/science.1172872, 2009.

Meinshausen, M., Smith, S. J., Calvin, K. V., Daniel, J. S., Kainuma, M. L. T., Lamarque, J.-F., Matsumoto, K., Montzka, S. A., Raper, S. C. B., Riahi, K., Thomson, A. M., Velders, G. J. M., and van Vuuren, D.: The RCP Greenhouse Gas Concentrations and 
their Extension from 1765 to 2300, Clim. Change, 109, 213-241, doi:10.1007/s10584-011-0156-z, 2011.

Misios, S. and Schmidt, H.: The role of the oceans in shaping the tropospheric response to the 11 year solar cycle, Geophys. Res. Lett, 401 6373-6377, doi:10.1002/2013GL058439, 2013.

Mitchell, D.: Attributing the forced components of observed stratospheric temperature variability to external drivers, Q. J. Roy. Meteor. Soc, 142, 1041-1047, doi:10.1002/qj.2707, 2016.

Mitchell, D., Gray, L., Fujiwara, M., Hibino, T., Anstey, J., Ebisuzaki, W., Harada, Y., Long, C., Misios, S., Stott, P., and Tan, D.: Signatures of naturally induced variability in the atmosphere using multiple reanalysis datasets, Q. J. Roy. Meteo. Soc., 141, 2011-2031, doi:10.1002/qj.2492, 2015a.

Mitchell, D., Misios, S., Gray, L. J., Tourpali. K., Matthes. K., Hood. L., Schmidt. H., Chiodo, G., Thiéblemont, R., Rozanov, E., Shindell, D., and Krivolutsky, A.: Solar signals in CMIP-5 simulations: The stratospheric pathway, Q. J. Roy. Meteor. Soc, doi:10.1002/qj.2530, 2015 b.

Nakamura, H., Sampe, T., Goto, A., Ohfuchi, W., and Xie, S.-P.: On the importance of midlatitude oceanic frontal zones for the mean state and dominant variability in the tropospheric circulation, Geophys. Res. Lett., 35, L15709, doi:10.1029/2008GL034010, 2008.

NASA: Aerosols Optical Depth, available at: http://data.giss.nasa. gov/modelforce/strataer/tau.line_2012.12.txt, last access: 18 October 2016.

Nitta, T. and Yoshimura, J.: Trends and interannual and interdecadal variations of global land surface air temperature, J. Meteorol. Soc. Japan, 71, 367-375, 1993.

NOAA: NOAA Extended Reconstructed SST v3b (ERSST), available at: http://www.esrl.noaa.gov/psd/data/gridded/data.noaa. ersst.html, last access: 18 October 2016.

Pittock, A. B.: A critical look at long-term sun-weather relationships, Rev. Geophys., 16, 400-420, 1978.

Rayner, N. A., Parker, D. E., Horton, E. B., Folland, C. K., Alexander, L. V., Rowell, D. P., Kent, E. C., and Kaplan A.: Global analyses of sea surface temperature, sea ice, and night marine air temperature since the late nineteenth century, J. Geophys. Res., 108, 4407, doi:10.1029/2002JD002670, 2003.

Roy, I. and Haigh, J. D.: Solar cycle signals in the pacific and the issue of timings, J. Atmos. Sci., 69, 1446-1451. doi:10.1175/JASD-11-0277.1, 2012.

Sato, M., Hansen, J. E., McCormick, M. P., and Pollack, J. B.: Stratospheric aerosol optical depth, 1850-1990, J. Geophys. Res., 98, 22987-22994, 1993.

Scaife, A. A., Ineson, S., Knight, J. R., Gray, L. J., Kodera, K., and Smith, D. M.: A mechanism for lagged North Atlantic climate response to solar variability, Geophys. Res. Lett., 40, 434-439, doi:10.1002/grl.50099, 2013.

Shindell, D. T., Schmidt, G. A., Miller, R. L., and Rind, D.: Northern Hemisphere winter climate response to greenhouse gas, ozone, solar, and volcanic forcing, J. Geophys. Res., 106, 71937210, doi:10.1029/2000JD900547, 2001.

SIDC: Solar Sunspot Number, available at: http://www.sidc.be/ silso/datafiles, last access: 18 October 2016.

Simpson, I., Blackburn, M., and Haigh, J. D.: The role of eddies in driving the tropospheric response to stratospheric heating perturbations, J. Atmos. Sci., 66, 1347-1365, 2009.
Smith, T. M. and Reynolds, R. W.: Extended reconstruction of global sea surface temperatures based on COADS data (18541997), J. Climate, 16, 1495-1510, 2003.

Smith, T. M., Reynolds, R. W, Peterson, T. C., and Lawrimore, J.: Improvements NOAAs historical merged land-ocean temp analysis (1880-2006), J. Climate, 21, 2283-2296, 2008.

Souza-Echer, M. P., Echer, E., Rigozo, N. R., Brum, C. G. M., Nordemann, D. J. R., and Gonzalez, W. D.: On the relationship between global, hemispheric and latitudinal averaged air surface temperature (GISS time series) and solar activity, J. Atmos. Solar-Terr. Phy., 74, 87-93, 2012.

Stevens, M. J. and North, G. R.: Detection of the climate response to the solar cycle, J. Atmos. Sci., 53, 2594-2608, 1996.

Stott, P. A., Jones, G., and Mitchell, J. F. B.: Do models underestimate the solar contribution to recent climate change?, J. Climate, 16, 4079-4093, 2003.

Suh, Y.-C. and Lim, G.-H.: Effects of the 11-year solar cycle on the Earth atmosphere revealed in ECMWF reanalyses, Geophys. Res. Lett., 33, L24705, doi:10.1029/2006GL028128, 2006.

Svalgaard, L.: Calibrating the sunspotsumber using "the magnetic needle", CAWSES Newsletter, 4, 6-8, 2007.

Svensmark, H. and Friis-Christensen, E.: Variation of cosmic ray flux and global cloud coverage - A missing link in solar-climate relationships, J. Atmos. Sol.-Terr. Phy,. 59, 1225-1232, 1997.

Tapping, K. F.: The $F 10.7 \mathrm{~cm}$ solar radio flux $\left(\mathrm{F}_{10.7}\right)$, Space Weather, 11, 394-406, doi:10.1002/swe.20064, 2013.

Thiéblemont, R., Matthes, K., Omrani, N.-E., Kodera, K., and Hansen, F.: Solar forcing synchronizes decadal North Atlantic climate variability, Nature Communications, 6, 8268, doi:10.1038/ncomms9268, 2015.

Thompson, D. W. J. and Wallace, J. M.: Annular modes in the extratropical circulation. Part I: Month-to-month variability, J. Climate, 13, 1000-1016, 2000.

Thompson, D. W. J., Solomon, S., Kushner, P. J., England, M. H., Grise, K. M., and Karoly, D. J.: Signatures of the Antarctic ozone hole in Southern Hemisphere surface climate change, Nat. Geosci., 4, 741-749, 2011

Thuburn, J. and Craig, G. C.: Stratospheric influence on tropopause height: The radiative constant, J. Atmos. Sci., 57, 17-28, 2000.

Tiao, G., Reinsel, G., Xu, D., Pedrick, J., Zhu, X., Miller, A., DeLuisi, J., Mateer, C., and Wuebbles, D.: Effects of autocorrelation and temporal sampling schemes on estimates of trend and spatial correlation, J. Geophys. Res.-Atmos., 95, 20507-20517, doi:10.1029/JD095iD12p20507, 1990.

Tung, K. K. and Zhou, J. S.: The Pacific's response to surface heating in $130 \mathrm{yr}$ of SST: La Niña-like or El Niño-like? J. Atmos. Sci., 67, 2649-2657, 2010.

UVIC: $\mathrm{CO}_{2}$ concentration dataset, available at: http://climate.uvic. ca/EMICAR5/forcing_data/RCP85_MIDYR_CONC.DAT, last access: 18 October 2016.

van Loon, H., Meehl, G. A., and Shea, D. J.: Coupled air-sea response to solar forcing in the Pacific region during northern winter, J. Geophys. Res., 112, D02108, doi:10.1029/2006JD007378, 2007.

Wang, B.: On the annual cycle in the tropical eastern central Pacific, J. Climate, 7, 1926-1942, 1994.

Wang, Y.-M., Lean, J., and Sheeley Jr, N. R.: Modeling the Sun's magnetic field and irradiance since 1713, Astrophys. J., 625, 522-538, 2005. 
Wang, D., Wang, C., Yang, X., and Lu, J.: Winter Northern Hemisphere surface air temperature variability associated with the Arctic Oscillation and North Atlantic Oscillation, Geophys. Res. Lett., 32, L16706, doi:10.1029/2005GL022952, 2005.

Wolter, K. and Timlin, M. S.: El Niño/Southern Oscillation behaviour since 1871 as diagnosed in an extended multivariate ENSO index (MEI.ext), Int. J. Climatol., 31, 1074-1087, doi:10.1002/joc.2336, 2011.

Xie, S.-P.: The shape of continents, air-sea interaction, and the rising branch of the Hadley circulation, in: The Hadley Circulation: Past, Present and Future, edited by: Diaz, H. F. and Bradley, R. S., Kluwer Academic Publishers, Dordrecht, the Netherlands, 121152, 2004.
Xie, S.-P. and Tanimoto, Y.: A pan-Atlantic decadal climate oscillation, Geophys. Res. Lett., 25, 2185-2188, 1998.

Yukimoto, S. and Kodera, K.: Annular modes forced from the stratosphere and interactions with the ocean, J. Meteorol. Soc. Jpn., 85, 943-952, 2007.

Yukimoto, S., Noda, A., Uchiyama, S., Kusunoki, T., and Kitoh, A.: Climate change of the twentieth trough twenty-first centuries simulated by the MRI-CGCM2.3, Pap. Meteorol. Geophys., 56, 9-24, 2006.

Zhou, J. S. and Tung, K. K.: Solar cycles in 150 years of global sea surface temperature data, J. Climate, 23, 3234-3248, 2010. 